\title{
The Nocturnal Evolution of Atmospheric Structure in a Basin as a Larger-Scale Katabatic Flow Is Lifted over Its Rim 0
}

\author{
C. David Whiteman, Manuela Lehner, ${ }^{a}$ And Sebastian W. Hoch \\ University of Utah, Salt Lake City, Utah
}

BIANCA ADLER AND NORBERT KALTHOFF

Karlsruhe Institute of Technology, Karlsruhe, Germany

Roland VogT AND IRIS FEIGENwINTER

University of Basel, Basel, Switzerland

THOMAS HAIDEN

European Centre for Medium-Range Weather Forecasts, Reading, United Kingdom

\author{
MATTHEw O. G. HiLls ${ }^{\mathrm{b}}$ \\ University of Utah, Salt Lake City, Utah
}

(Manuscript received 3 June 2017, in final form 11 January 2018)

\begin{abstract}
The successive stages of nocturnal atmospheric structure inside a small isolated basin are investigated when a katabatically driven flow on an adjacent tilted plain advects cold air over the basin rim. Data came from Arizona's Meteor Crater during intensive observing period 4 of the Second Meteor Crater Experiment (METCRAX II) when a mesoscale flow above the plain was superimposed on the katabatic flow leading to a flow acceleration and then deceleration over the course of the night. Following an overflow-initiation phase, the basin atmosphere over the upwind inner sidewall progressed through three stages as the katabatic flow accelerated: 1) a cold-air-intrusion phase in which the overflowing cold air accelerated down the upwind inner sidewall, 2) a bifurcation phase in which the katabatic stable layer lifted over the rim included both a nonnegatively buoyant upper layer that flowed horizontally over the basin and a negatively buoyant lower layer (the cold-air intrusion) that continued on the slope below to create a hydraulic jump at the foot of the sidewall, and 3) a final warm-air-intrusion phase in which shear instability in the upper overflowing layer produced a lee wave that brought warm air from the elevated residual layer downward into the basin. Strong winds during the third phase penetrated to the basin floor, stirring the preexisting, intensely stable, cold pool. Later in the night a wind direction change aloft decelerated the katabatic wind and the atmosphere progressed back through the bifurcation and cold-air-intrusion phases. A conceptual diagram illustrates the first four evolutionary phases.
\end{abstract}

Supplemental information related to this paper is available at the Journals Online website: https://doi.org/10.1175/JAMCD-17-0156.s1.

${ }^{\text {a }}$ Current affiliation: University of Innsbruck, Innsbruck, Austria.

${ }^{\mathrm{b}}$ Current affiliation: Weathernews, Soest, Netherlands.

Corresponding author: C. David Whiteman, dave.whiteman@ utah.edu

\section{Introduction}

The first Meteor Crater Experiment (METCRAX; Whiteman et al. 2008) was conducted in Arizona's Barringer Meteorite Crater (also called Meteor Crater) in October of 2006 to investigate the nocturnal buildup of stable boundary layers in the crater basin. This experiment resulted in the serendipitous discovery of an unexpected 
phenomenon-the occasional occurrence of strong turbulent nocturnal flows near the base of the upwind inner sidewall. Although the observational network was not ideally placed to investigate these flows, initial analyses identified the phenomenon as a downslope windstormtype flow (Adler et al. 2012) in which warm air from aloft descended into the lee of the upwind crater rim. A Second Meteor Crater Experiment (METCRAX II; Lehner et al. 2016a) was then designed to investigate this phenomenon and the related cold-air intrusions (Whiteman et al. 2010; Haiden et al. 2011; Kiefer and Zhong 2011) that come continuously over the crater rim from the southwest at night as a katabatic flow develops on the adjacent plain. METCRAX II was conducted in October of 2013, and the strongest, best-observed downslope windstorm-type flow, which occurred during the fourth intensive observing period (IOP4) on the night of 19-20 October 2013, is the topic of this paper. Dual-Doppler wind data and frequent tethersonde soundings allow, for the first time, an investigation of the spatiotemporal development and relationships between the evolving wind and temperature structure inside and outside the crater basin.

The paper is structured as follows: Section 2 surveys literature on the current understanding of similar phenomena observed in other locations and in the Meteor Crater. The topography, ground cover, synoptic situation, and experimental setup are described in section 3. Section 4 presents analyses, section 5 discusses the most interesting features of the phenomenon, and section 6 provides a summary.

\section{Background}

As air flows past three-dimensional, isolated topography, the resulting interactions with the terrain can produce multiple flow responses, including a splitting of the flow around the obstacle; flow over the obstacle; the formation of wakes; and the formation of mountain waves, wave breaking, and downslope windstorms over and in the lee of the obstacle (e.g., Smith 1989). Downslope windstorms have been well studied and have been observed in flows over ridges throughout the world [reviewed, e.g., by Jackson et al. (2013)]. In contrast, there have been few studies of flows into basins. A similarity of the flows might be expected given that in both cases the flows come over a relatively high terrain (mountain or plain) to descend lee slopes. Our observations of strong gusty nighttime downslope winds on the lower inner sidewall of the Meteor Crater basin during the METCRAX and METCRAX II field experiments were the motivation for two sets of idealized numerical simulations designed to investigate the similarities between these katabatically driven flows and downslope windstorms.
Using two-dimensional simulations, Lehner et al. (2016b) simulated the effects of basin size, upstream flow, atmospheric stability, and uniform background winds on flow regimes in a basin embedded on a $1^{\circ}$ tilted plain on which a katabatic flow developed naturally. Flow responses were of four types similar to those seen in the lee of mountain ridges: wakes over the upstream basin sidewall, sweeping of the basin atmosphere, waves over the basin, and stagnation over the upstream basin sidewall accompanied by a hydraulic jump. Rotunno and Lehner (2016) determined the two-dimensional flow regimes that might occur within a depression embedded in a smooth horizontal plain when a heightindependent ambient flow was imposed on a two-layer atmosphere with a statically stable lower layer and a neutral layer aloft. Steady-state flow solutions were presented in a regime diagram using three nondimensional numbers that characterize the basin and the upstream flow parameters. The various flow regimes included sweeping and stagnating flow, lee waves, hydraulic jumps, internal wave breaking, and upstream-propagating waves.

Although there are similarities between flows in the lee of mountains and flows descending into basins (e.g., strong, gusty, and sometimes intermittent winds on the lee slope when relatively strong winds cross the barrier at a perpendicular angle and a temperature inversion is present in the incoming flow over the obstacle), there are also differences. The gusty downslope winds are much weaker at Meteor Crater, in keeping with the reduced topographic relief. The downslope-windstorm-type flows observed at Meteor Crater occur at nighttime when katabatic flows are present on the surrounding plain, whereas synoptically driven downslope windstorms over mountain barriers can occur at any time of day.

\section{Meteor Crater topography, observations, data conventions, definitions, and synoptic weather}

\section{a. The Meteor Crater topography and ground cover}

The crater has been fully described in previous publications (e.g., Kring 2007; Whiteman et al. 2008; Lehner et al. 2016a), and so a succinct summary here will suffice. The near-circular crater with a diameter of $1200 \mathrm{~m}$ is $170 \mathrm{~m}$ deep and has a rim that projects $30-50 \mathrm{~m}$ above the extensive surrounding mesoscale plain. The plain descends from the Mogollon Rim, a line of high plateaus southwest of the crater, with a mean slope angle of $1^{\circ}$ in the vicinity of the crater. The plain is on the western sidewall of the Little Colorado River valley, which drains to the northwest. The Meteor Crater and its surroundings are in a semiarid region with a sparse ground cover of 


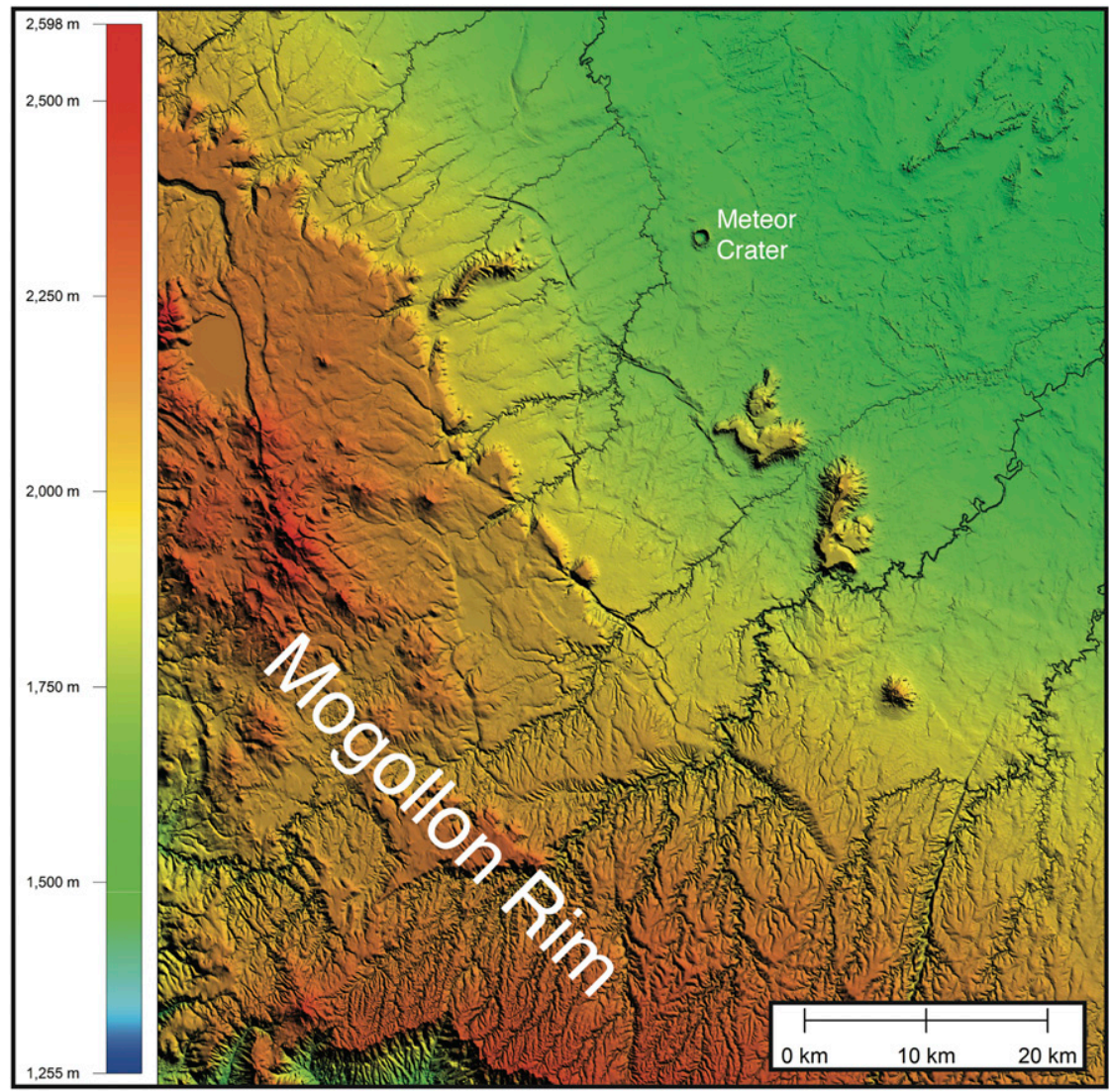

FIG. 1. Topographic map of the Meteor Crater and its surroundings, with elevation (m MSL) indicated in the legend. The crater is on the southwest side of the Little Colorado River drainage, which flows to the northwest. North is at the top of the figure.

shrubs and grasses. The main topographic features surrounding the crater are shown in Fig. 1 in which the crater is seen as a small pockmark on an extensive sloping plain.

\section{b. Measurement sites}

The meteorological measurements used in this paper and their locations are indicated in Fig. 2. Lehner et al. (2016a) provided a full listing of equipment, locations, and observation frequencies, and therefore we present a summary here. A 40-m tower at the "RIM" location had temperature, humidity, and 3D sonic wind measurements at 5-m height intervals. A 50-m tower at the "NEAR" location was equipped similarly, but with a 3-m height substituted for the 5-m height. Additional sonic-anemometer wind data came from the "SSW4" and "SSW2" masts on the upper and lower south-southwest sidewall. The planar-fit method (Wilczak et al. 2001) was used to correct for sonic tilt, rotating the data into a slope coordinate system with zero vertical velocity averaged over the entire field-deployment period. The planar fit at RIM, however, was applied using data only from wind directions between $142.5^{\circ}$ and $262.5^{\circ}$.
Scanning Doppler lidars were located on the crater's north rim and floor. They were programmed to execute multiple scanning strategies. Coplanar range-height indicator (RHI) scans along the $15^{\circ}-195^{\circ}$ azimuth indicated in Fig. 2 are featured in this paper, and an entire set of dual-Doppler wind-retrieval figures is available in the online supplemental information (see the Fig_SI-1 animation and caption files at https://doi.org/10.1175/JAMC-D-17-0156.s1). The dual-Doppler retrievals were calculated from continuous coplanar RHI scans from the "NRIM" (elevation angles from $-10^{\circ}$ to $20^{\circ}, 25-\mathrm{m}$ range-gate length, and scan resolution of $0.75^{\circ}$ ) and "FLR" (elevation angles from $10^{\circ}$ to $150^{\circ}, 24-\mathrm{m}$ range-gate length, and scan resolution of $1.4^{\circ}$ ) lidar locations over 2.5- and 5-min intervals on a $25 \mathrm{~m} \times 25 \mathrm{~m}$ grid. Measurements of the full surface energy balance, including four-component radiation measurements and ground, sensible, and latent heat fluxes, were made at the FLR, NEAR, and "FAR" locations. Tethered balloon soundings were made at $\sim 20$-min intervals from the "TS-B," TS-SW," and "TS-C" locations to heights well above the crater rim, measuring temperature, humidity, 

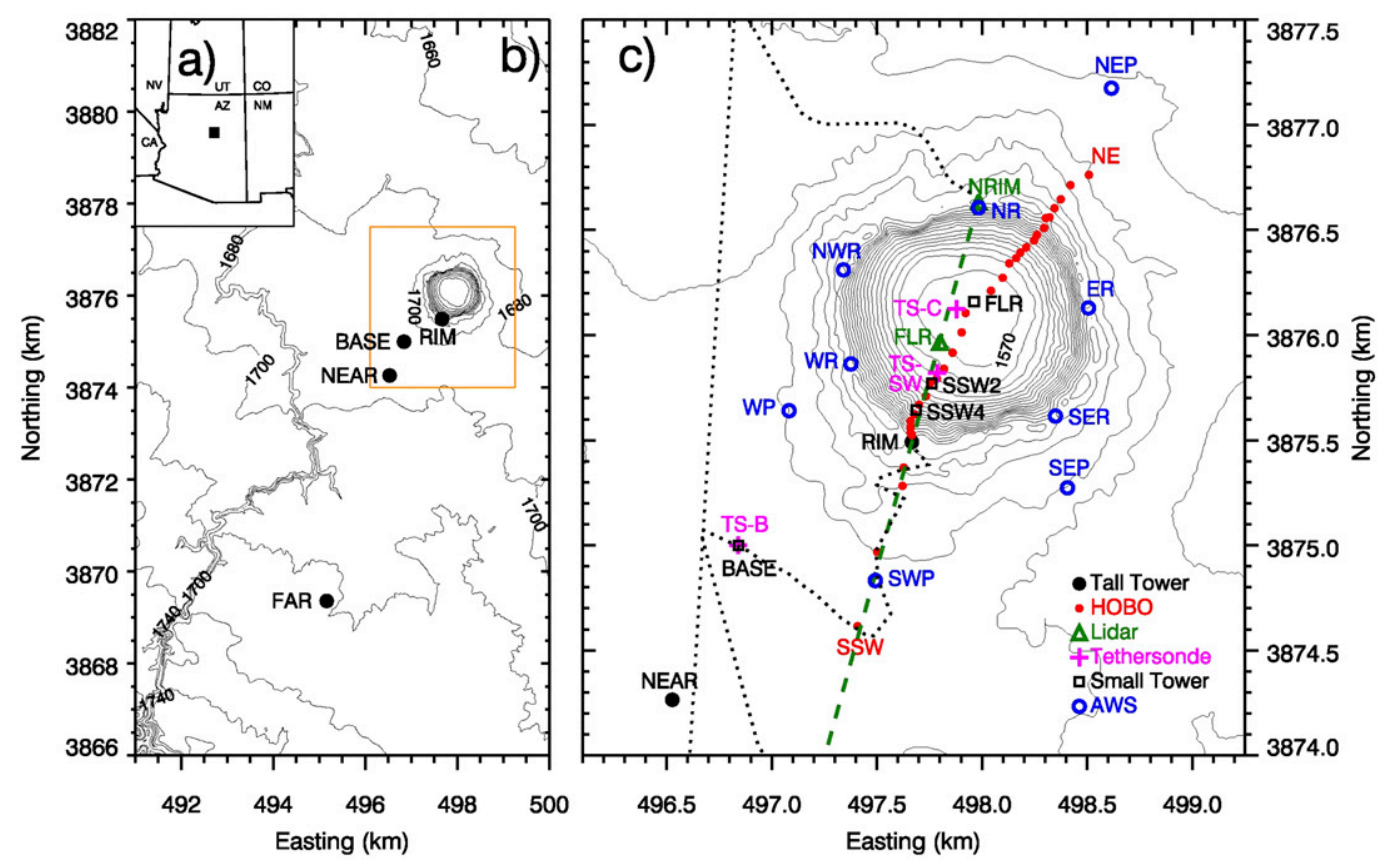

FIG. 2. Map of (a) the crater's location in the southwestern United States, (b) the topography and measurement sites in the crater's surroundings, and (c) the topography and measurement sites in and near the crater, with north at the top of the figures. Panels (b) and (c) are universal transverse Mercator zone 12S projections, with contour intervals at 20 and $10 \mathrm{~m}$, respectively. The dashed green line shows the location of the vertical dual-lidar cross section. The dotted black lines in (c) are roads.

wind speed, and wind direction. Battery changes sometimes resulted in larger time gaps between soundings. The TS-C and TS-SW soundings were conducted synchronously. Lines of automatic Onset Computer Corporation "HOBO" temperature dataloggers exposed at $1.2 \mathrm{~m}$ above ground level (AGL) ran from the basin center up the sidewalls and out onto the adjacent plain. Instantaneous temperature samples were taken at 2.5-min intervals. Data from the northeast and south-southwest HOBO lines (designated as NE and SSW, respectively) are featured in this paper. The two rim HOBOs on these lines are designated $\mathrm{NE}^{\prime}$ and $\mathrm{SSW}^{\prime}$, respectively. Automatic weather stations were located at various sites on the rim and the surrounding plain.

\section{c. Data conventions}

Several conventions will be employed in this paper. Times are mountain standard time (MST) applied to the ends of any averaging intervals, unless otherwise stated. Astronomical sunset was at $1742 \mathrm{MST}$, and sunrise was at 0635 MST. Elevations are in meters above mean sea level (MSL), and heights are in meters AGL. Because many of our observation sites recorded temperature but not pressure, we use an alternate means of estimating potential temperature that is an accurate approximation to the classical Poisson method (see the appendix). This height-adjusted temperature $\left(\theta ;{ }^{\circ} \mathrm{C}\right)$, which we will call potential temperature, was calculated using $\theta=T+\Gamma\left(z-z_{f}\right)$, where $T$ is temperature $\left({ }^{\circ} \mathrm{C}\right), \Gamma\left(=0.0098^{\circ} \mathrm{Cm}^{-1}\right)$ is the dryadiabatic lapse rate, $z$ is elevation, and the crater floor elevation $z_{f}(=1564 \mathrm{~m})$ is the reference elevation. Although potential temperatures are denoted in degrees Celsius, potential temperature differences and gradients are reported in kelvins $(\mathrm{K})$ and kelvins per kilometer.

\section{d. Definitions}

During IOP4, the atmosphere inside the crater evolved through a series of phases. Before discussing these phases, we refer to sample potential temperature soundings in Fig. 3 to introduce terminology and define phase characteristics.

The dividing streamline (Fig. 3a) is the central streamline upwind of the crater and outside its influence that, when rising up the outer sidewall of the crater, just touches the rim. This special definition differs from the more general definition (e.g., Glickman 2000; Leo et al. 2016) in that a dividing streamline is defined only for times at which the stable katabatic air on the plain overflows the rim. Flow approaching the crater below the dividing streamline will split horizontally around the crater while flow above the dividing streamline will be lifted over the rim. The dividing streamline elevation is estimated as the elevation on the 

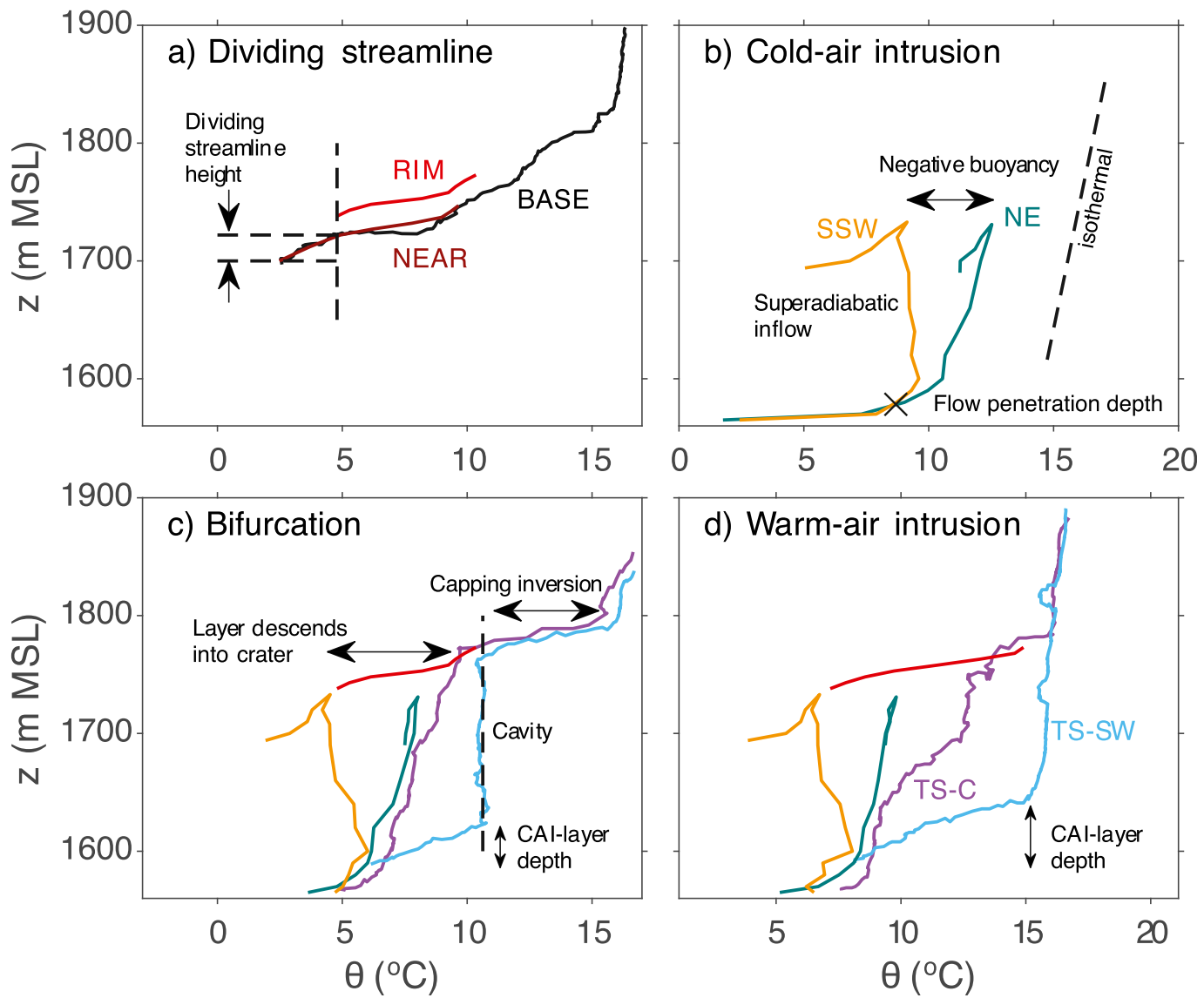

FIG. 3. Sample potential temperature profiles illustrating (a) dividing streamline elevation, (b) CAI along the upwind inner sidewall, (c) bifurcation, and (d) WAI over the upwind inner sidewall. Data come from 0400, 2120, 0400, and 2300 MST for (a)-(d), respectively. The lines of HOBOs extend over the rim and out onto the adjacent plain (see Fig. 2), and therefore potential temperature profiles include data from both the inner and outer sidewalls.

NEAR tower where the temperature matches that observed at the base of the RIM tower.

A continuous cold-air intrusion (CAI; Fig. 3b) occurs on the south-southwest inner sidewall when negatively buoyant air lifted over the south-southwest rim flows down the sidewall (Whiteman et al. 2010; Haiden et al. 2011). A diagnostic indicator of the CAI is a superadiabatic potential temperature profile on the SSW HOBO line (Whiteman et al. 2018; hereinafter W18).

A bifurcation (Bi; Fig. 3c) occurs when a stable layer coming over the rim splits into a lower negatively buoyant current that runs down the inner sidewall and an upper nonnegatively buoyant current that flows quasi horizontally over the crater (W18). A layer of warm, turbulent, neutrally stratified air (a "cavity" or wake) forms in the lee of the rim between the two currents. If the cavity extends far enough into the crater, the neutral layer will appear in the upper part of the TS-SW sounding with a capping stable layer at its top near rim level. The lower portion of the stable layer, which flows down the sidewall, will be present at the base of the sounding.

A warm-air intrusion (WAI; Fig. 3d) is produced by a lee wave that brings residual-layer (RL) air directly down into the basin above the southwest sidewall (Adler et al. 2012). If the wave extends downwind over the TS-SW site, no capping stable layer will be present at or just above the rim at this site.

\section{e. Weather conditions during IOP4}

IOP4 occurred during a period in which a blocking ridge off the Pacific Ocean coast brought high pressure and clear, undisturbed weather to the region. The ground was dry; the last rain $(5.7 \mathrm{~mm})$ had fallen on 10 October. The geopotential height gradient was weak above the region, supporting geostrophic winds from the northwest at $700 \mathrm{hPa}$. Three-hourly rawinsonde soundings in online supplemental Fig_SI-2 (https://doi.org/ 10.1175/JAMC-D-17-0156.s1) provide additional upper-air information. 


\section{Spatiotemporal evolution of potential temperature and wind}

A sequence of transitional phases in potential temperature and wind structure was observed inside the crater basin during IOP4, as driven by interactions between the crater and the approaching flow over the adjacent plain. The analysis begins with an overview of the boundary layer evolution on the plain. This is followed by a chronological description of the structural phases inside the crater and their relationship to the boundary layer structure of the approaching flow.

\section{a. Wind and potential temperature structure evolution outside the crater basin}

The evolution of vertical potential temperature and wind structure outside the crater was observed 1 ) at the "BASE" location with a sequence of tethered balloon ascents supplemented by Halo Photonics, Ltd., lidar velocity-azimuth display (VAD) scans (Browning and Wexler 1968) above $1950 \mathrm{~m}$ MSL (Fig. 4) and 2) with the NEAR and RIM towers (Fig. 5).

A stable boundary layer (SBL) begins to form on the plain in the late afternoon (Fig. 4a), growing upward into a quiescent afternoon RL. The elevation of the SBL top, as defined by a sharp potential temperature gradient decrease at the base of the RL, grows continuously upward overnight to reach $1780 \mathrm{~m}$ MSL by about 0312 MST. The SBL then becomes unsteady as differential cold-air advection begins aloft, and a stable sublayer develops within the SBL representing the depth of local katabatic cooling on the plain. The RL maintains a potential temperature gradient of $\partial \theta / \partial z=3 \mathrm{~K} \mathrm{~km}^{-1}$ and cools slowly during the night (Fig_SI-2; https://doi.org/ 10.1175/JAMC-D-17-0156.s1). Winds within the SBL, while initially upslope in late afternoon, quickly turn downslope and extend to heights above the top of the SBL, reaching $1810 \mathrm{~m}$ MSL by 2130 MST. At this time, however, a southwesterly mesoscale flow of undetermined origin in the RL becomes superimposed on the thermally driven katabatic wind, increasing the downslope wind speeds and greatly increasing the downslope flow depth (Fig. 4b). The depth and strength, however, decrease rapidly after about $0300 \mathrm{MST}$ as northwesterly winds develop above the crater rim, confining the thermally driven katabatic flow below $1750 \mathrm{~m}$ MSL. During the whole night, wind directions veer with height from south-southwest at the surface to southwest aloft. The dividing streamline height varies between 1710 and $1725 \mathrm{~m}$ MSL during most of the night (Fig. 4a), and the height of the wind speed maximum (Fig. 4b) increases steadily through 2230 MST, continues an unsteady increase to $0145 \mathrm{MST}$, and then drops to elevations near the crater rim for the remainder of the night. Downslope wind speeds at the height of the wind speed maximum at BASE and average wind speeds on the RIM and NEAR towers increase steadily to reach about $5 \mathrm{~m} \mathrm{~s}^{-1}$ by 2300 MST. Winds remain at this speed until about 0245 MST and then decrease during the remainder of the night (Fig. 4c). Weaker wind speeds at $80-120 \mathrm{~m}$ AGL exhibit a similar sinusoidal evolution.

Time series of potential temperature and wind at the various heights on the NEAR and RIM towers upwind of the crater basin are shown in Figs. 5a-e. The RIM tower data are shown alternatively as hourly vertical profiles in Figs. $5 \mathrm{~g}$ and $5 \mathrm{~h}$. Wind speeds at locations inside the crater, to be discussed later, are presented in Fig. 5f. Here we summarize the main evolutionary features. Potential temperatures on both the NEAR (Fig. 5a) and RIM (Fig. 5c) towers decrease rapidly in the evening and then more slowly during the remainder of the nighta feature typical of SBL development in katabaticflow situations (DeWekker and Whiteman 2006). Potential temperatures are lower on the RIM tower than on the NEAR tower at the same MSL elevation. The 2-m AGL potential temperature $7.2 \mathrm{~km}$ southsouthwest of the crater at FAR parallels the potential temperature at 3-m AGL on the NEAR tower, highlighting the along-slope homogeneity of the potential temperature structure within the terrainfollowing SBL. Initial drops in potential temperature at different sensor heights indicate when the SBL reaches that height. At the NEAR tower, the 3-m AGL level begins cooling by 1800 MST (Fig. 5a) and the SBL deepens to reach the tower top at $\sim 1910$ MST. Cold air from the deepening SBL on the upwind plain first reaches the base of the RIM tower at 1930 MST (Fig. 5c). A potential temperature drop at the tower top is difficult to ascertain from this figure, but Fig. $5 \mathrm{~g}$ indicates that the stable stratification has already reached the top by 2000 MST. The growing stable-layer depth exceeds the RIM tower height by around 2200 MST, and the potential temperature difference between the tower top and the first level reaches $8 \mathrm{~K}$ by midnight (Fig. $5 \mathrm{~g}$ ). Potential temperature oscillations occur on both towers during the rapid cooling period of SBL buildup and continue until 0100 MST on the RIM tower. The strongest potential temperature drops are often accompanied by wind speed increases, for example at 2100 and 2145 MST (Fig. 5c). Some oscillations (e.g., at 2100 and 2225 MST) can be identified at both NEAR and RIM (Figs. 5a,c), with oscillations at NEAR 


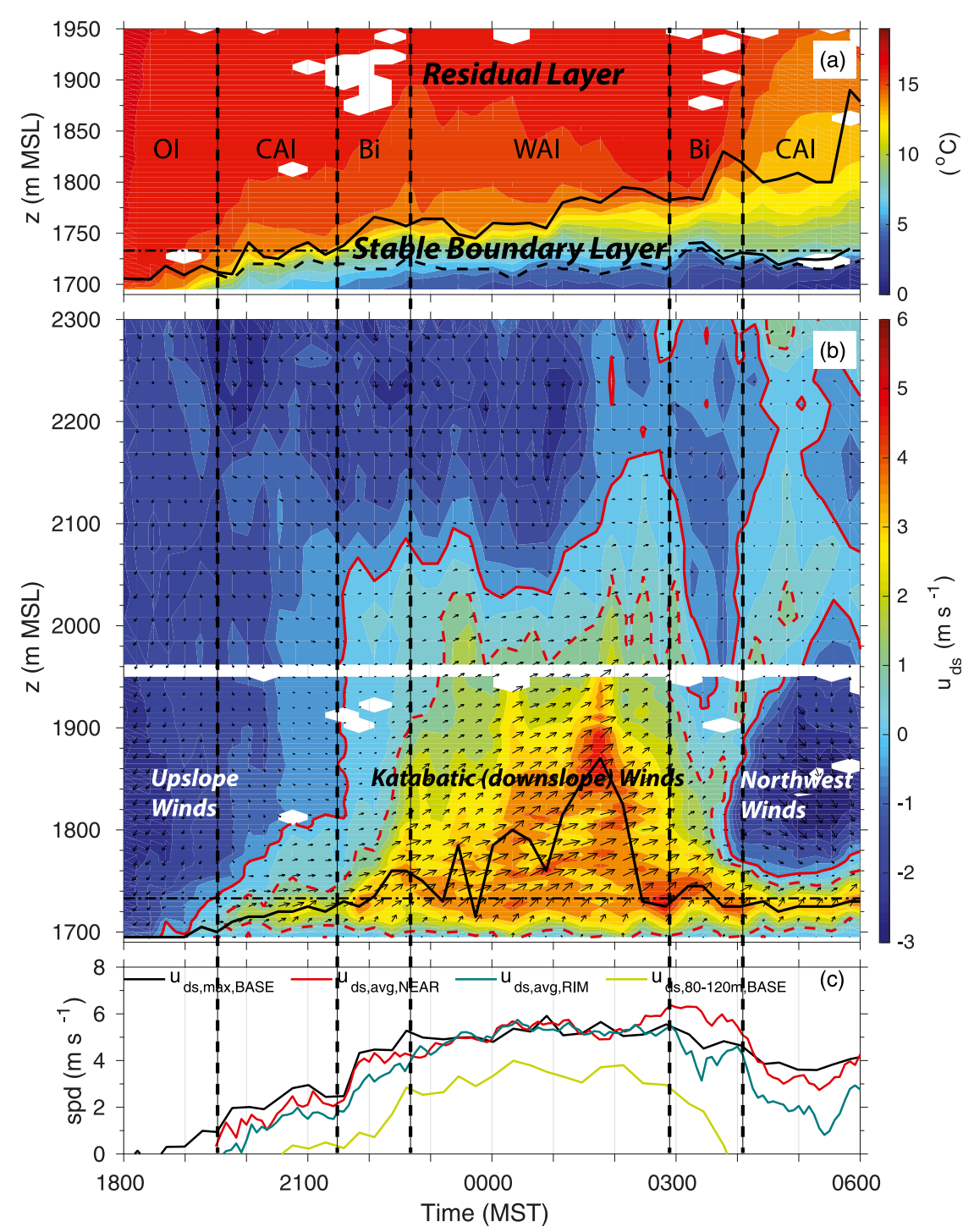

FIG. 4. Time-height cross sections of tethered-balloon (a) potential temperatures and (b) horizontal winds (arrows) above the upwind plain at BASE. The south-southwest rim elevation is indicated by horizontal dash-dotted lines. In (a), the dividing streamline (see section $4 \mathrm{~b}$ ) at NEAR and the SBL top at NEAR are shown as dashed and solid lines, respectively. The SBL top was determined subjectively from vertical potential temperature profiles, and a secondary stable-layer top (solid gray line) appeared in the profiles after $\sim 0315$ MST. Color contours in (b) are downslope wind components along a $15^{\circ}$ azimuth. Winds below and above $1950 \mathrm{~m}$ MSL are from tethered balloon ascents and lidar VAD scans, respectively. Tethersonde data are 5-m bin averages every $15 \mathrm{~min}$. Lines in (b) are downslope wind speed maximum elevations (solid black) and the 0 and $1 \mathrm{~m} \mathrm{~s}^{-1}$ downslope (15 ${ }^{\circ}$ azimuth) wind speed isotachs (red solid and red dashed lines, respectively). Also shown are (c) the maximum downslope wind component at BASE, the mean downslope wind component in the flowing layer above the dividing streamline at NEAR and for a layer of equal depth at RIM, and the mean downslope wind component in the 80-120-m AGL layer at BASE. Phases are indicated by the abbreviations in (a) (see text) and are bounded by vertical dashed lines.

preceding those at RIM by about $8 \mathrm{~min}$, corresponding roughly to the advection time over the $1500-\mathrm{m}$ distance between the two towers at wind speeds of $2-3 \mathrm{~m} \mathrm{~s}^{-1}$. Oscillations in drainage flows have been previously investigated [see, e.g., the review by Zardi and Whiteman (2013)]. 

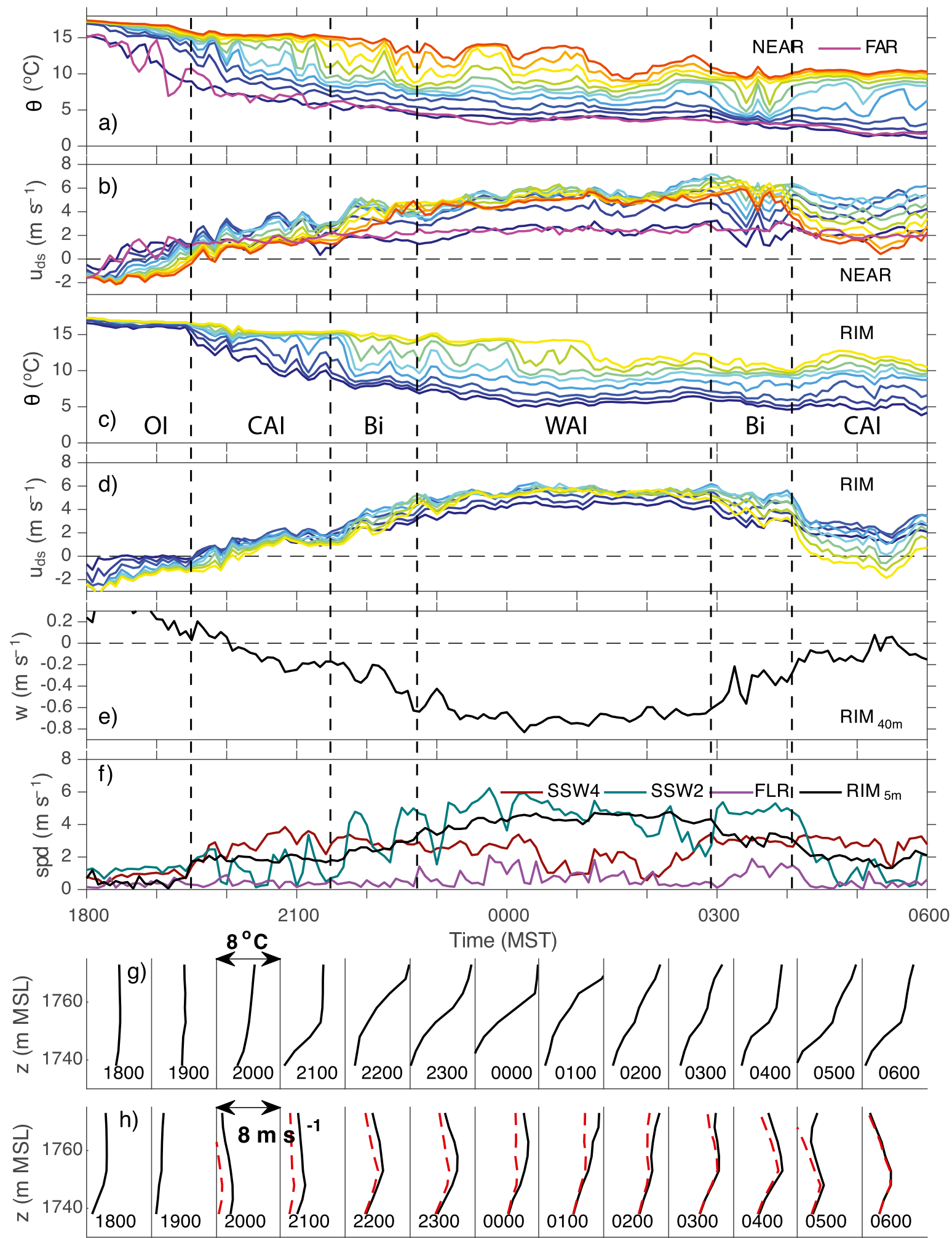

FIG. 5. Respective potential temperature and downslope wind component (along $15^{\circ}$ azimuth) time series at (a),(b) NEAR and (c),(d) RIM. Measurement heights $(3,10,15,20, \ldots, 50 \mathrm{~m}$ AGL at NEAR and 5, 10, 15, ., $40 \mathrm{~m}$ AGL at RIM) increase from dark blue to orange. The 2-m AGL potential temperature and the 3-m AGL downslope wind speed component at FAR (purple) have been added to (a) and (b), respectively. (e) The 40-m AGL vertical velocity at RIM. (f) Wind speeds at SSW4, SSW2, and FLR and at $5 \mathrm{~m}$ AGL at RIM. Hourly (g) potential temperature and (h) total (black) and downslope (red) wind speed profiles at RIM (upslope components at 1800 and 1900 MST are not plotted). Named evolutionary phases are bounded by vertical dashed lines. All data are 5-min means. Vertical profiles are a 5-min mean ending at the hour indicated. 

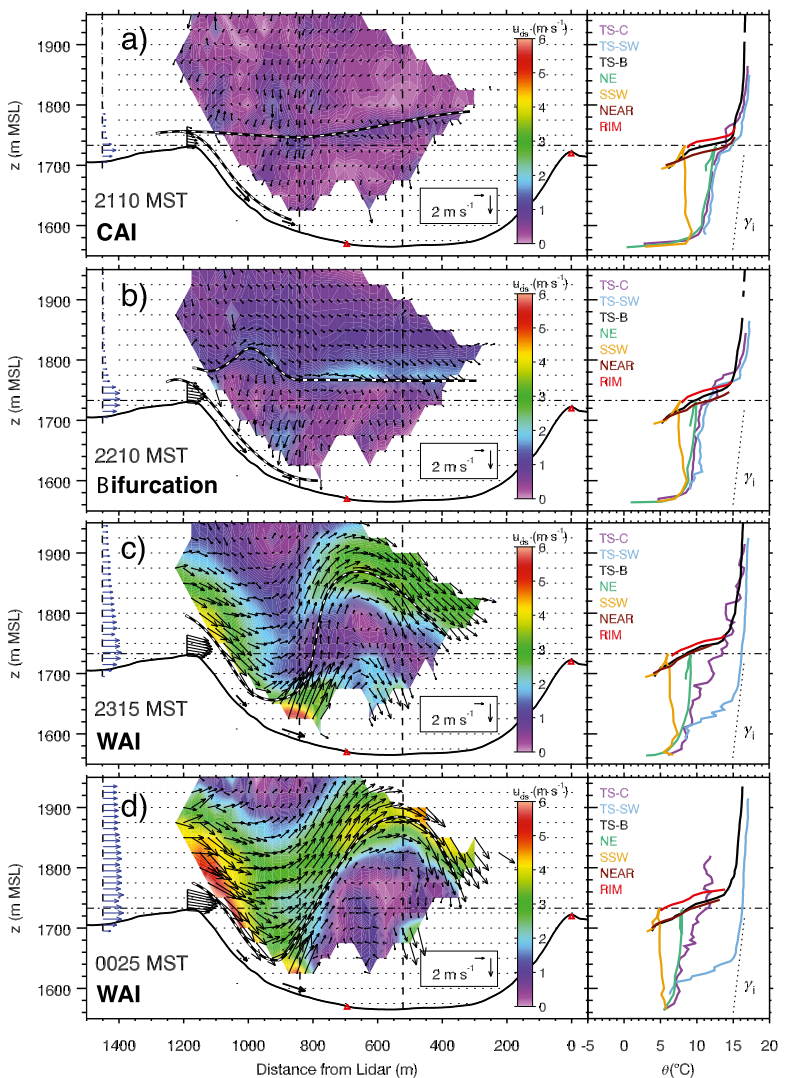
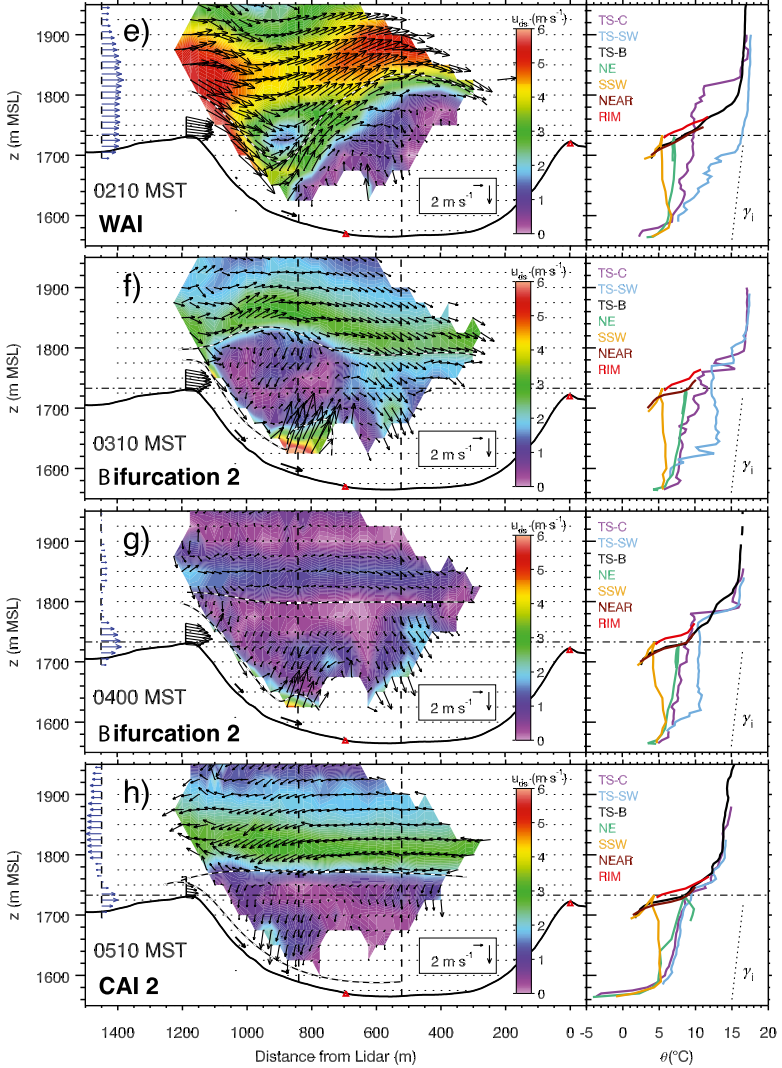

FIG. 6. Wind and potential temperature structure during IOP4 within a $15^{\circ}$ azimuth vertical plane through the crater (location in Fig. 2). Terrain is indicated by a solid black line, and rim elevation is shown by a horizontal dot-dashed line. Off-plane data are projected perpendicularly onto the plane. The phases are indicated. The data shown are 5-min averages ending at the time indicated, except for tethersonde soundings, which are the closest in time within $\pm 7.5 \mathrm{~min}$ of the averaging-interval midpoint. In the left part of each panel, the black vectors are 2D $(u, w)$ winds. TS-B wind profiles (blue vectors at left) have no $w$ component and are offset from its plain location (moved closer to the crater). TS-SW and TS-C sites are at the dashed vertical lines. Winds come from dual-Doppler retrievals (red triangles are lidar locations; the north-rim lidar is the $x$-coordinate origin), the RIM tower, the BASE tethersonde, and the SSW4 and SSW2 sites. Color contours (see legend) indicate wind speeds within the plane. The upper and lower black and white dashed lines are the RL base and slope SBL elevations, respectively, as determined from sharp decreases in vertical potential temperature gradient from measurement sites in the right part of each panel. The wind field is used for guidance between sites. The RL and SBL elevations are identical in the WAI phase. The right part of each panel shows the potential temperature soundings at the sites shown in the legend. The sloping dotted lines indicate an isothermal lapse rate.

Wind speeds evolve sinusoidally over the night at both the NEAR (Fig. 5b) and RIM (Fig. 5d) towers, as seen previously in Fig. 4c. Downslope winds begin at the lowest levels of the NEAR and RIM towers at 1820 and 1920 MST, respectively, but they climb the RIM tower much more quickly than the NEAR tower. The jetlike katabatic wind maximum climbs the RIM tower, exceeding the tower height after midnight (Fig. 5h). The jetlike profile is reestablished within the RIM tower layer, however, by approximately 0300 MST. Vertical shear is much stronger on the NEAR tower than on the RIM tower (Figs. 5b,d). The vertical velocity at RIM, initially positive, becomes negative once the downslope flow reaches the tower top, and the sinusoidal shape of the vertical velocity time series is a mirror image to the RIM wind speed curves (Fig. 5e).

\section{$b$. Wind and potential temperature structure evolution inside the crater}

The atmospheric structure inside the crater went through a sequence of phases whose approximate timing is given by the vertical lines superimposed on Figs. 4 and 5, which illustrated potential temperature and wind structure outside the crater basin. In this section, the phases are discussed chronologically using hourly potential temperature profiles and winds on a cross section through the crater basin (Fig. 6). Data come from the TS-B, TS-SW, and TS-C tethersondes, the BASE and RIM towers, the NE and SSW HOBO 
lines, the short-tower observations at SSW4 and SSW2, and dual-Doppler wind retrievals (Cherukuru et al. 2015) within and above the crater. The HOBO temperature sensors experience somewhat lower potential temperatures than the adjacent free atmosphere because they are exposed near the ground in the terrain-following stable layer.

\section{1) OVERFLOW-INITIATION PHASE, FROM LATE AFTERNOON TO 1930 MST}

During the overflow-initiation (OI) phase the atmosphere inside the crater develops locally without significant influence from outside. Separate stable boundary layers form inside the crater and on the adjacent plain following the reversal of the local radiation and energy budgets (online supplemental Fig_SI-3; https://doi.org/ 10.1175/JAMC-D-17-0156.s1). The cold air within the SBLs flows down the topographic gradient as a katabatic flow, replacing the afternoon upslope flows on the plain (Savage et al. 2008) and basin sidewalls (Martinez-Villagrassa et al. 2013). The surface radiation and energy budgets reverse earlier in the crater than on the plain because of the shadow that is cast into the basin from the south and west rims by the setting sun (Hoch and Whiteman 2010; Hoch et al. 2011; Martinez-Villagrassa et al. 2013). Inside the basin, the decrease in the crater radius as the floor is approached will cause locally developed downslope flows on the sidewalls to converge on and over the valley floor, with buoyancy forces tending to level the isentropes (Zardi and Whiteman 2013). During this phase the SBL inside the crater develops a vertical potential temperature structure in which a shallow, strongly stable, relatively quiescent cold pool forms on the crater floor and the entire basin atmosphere above the cold pool begins to stabilize (Whiteman et al. 2008). The OI phase ends at 1930 MST when the cold air on the plain first reaches the base of the RIM tower (Fig. 5c). This occurs about $30 \mathrm{~min}$ before the SBL on the plain reaches this elevation (Fig. 3a), illustrating the role of the katabatic flow, whose maximum speed is about $2 \mathrm{~m} \mathrm{~s}^{-1}$ (Figs. $4 \mathrm{c}$ and $5 \mathrm{~b}$ ), in lifting air over the rim. The time of overflow initiation thus depends not only on the rim height and the rate of upward growth of the SBL on the plain, but also on the strength of the katabatic flow.

\section{2) Cold-AIR-INTRusion PHASE, 1930-2130 MST}

Cold-air intrusions have been previously studied at Meteor Crater (Whiteman et al. 2010; W18; Haiden et al. 2011; Kiefer and Zhong 2011) but will be summarized here for IOP4. The CAI phase begins at 1930 MST. As the SBL over the plain deepens and the katabatic flow strengthens,

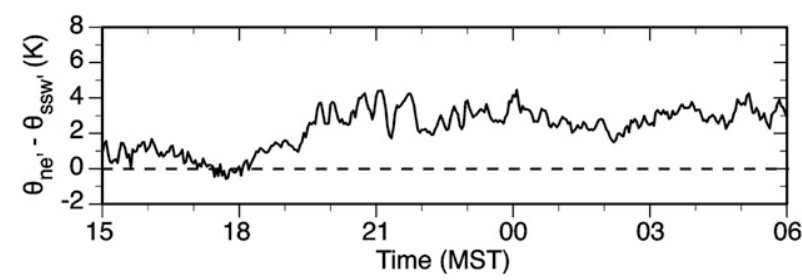

FIG. 7. Potential temperature difference between the upwind rim $\left(\mathrm{SSW}^{\prime}\right)$ and downwind rim $\left(\mathrm{NE}^{\prime}\right)$.

the layer of cold air carried over the rim also deepens (Fig. 5c). Sudden decreases in potential temperature indicate the times at which the SBL engulfs individual tower levels. The vertical potential temperature structure of the overflow closely resembles that above the dividing streamline on the plain when displaced upward by the elevation difference between the dividing streamline and the rim (Figs. 3a and 6a), indicating that the lifting is adiabatic (W18). The dividing streamline elevation on the NEAR tower at 1930 MST is $1710 \mathrm{~m}$ MSL (15 m AGL) but is typically 1715-1720 m MSL (20-25 m AGL) during most of the night (Fig. 4a). For comparison, the elevation difference between NEAR and RIM is $38 \mathrm{~m}$. In accordance with previous studies (e.g., W18), the flow splits to the left and right around the crater below the dividing streamline and a warm well-mixed wake forms in the lee of the crater (online supplemental Fig_SI-4a; https://doi.org/10.1175/ JAMC-D-17-0156.s1). These flow features persist all night (cf. Fig_SI-4b; https://doi.org/10.1175/JAMC-D-170156.s1). As CAIs continue to bring cold air over the rim, compensatory outflows occur over the downwind rim.

Because the continuous inflow over the upwind rim is colder than air at the downwind rim at $\mathrm{NE}^{\prime}$ (Fig. 7) and, as it turns down the sidewall, remains colder than the environmental air within the crater as represented by the NE, TS-SW, and TS-C profiles (Fig. 6a), it has the negative buoyancy (Byers 1959) to accelerate down the sidewall as a CAI (Whiteman et al. 2010; W18; Haiden et al. 2011). Buoyancy acceleration is proportional to horizontal temperature or potential temperature differences between a parcel and its undisturbed environment [Byers 1959, Eq. (7-80)]. At any given time, we consider the NE profile, because of its relatively undisturbed location on the crater sidewall opposite the intrusion, to be the most suitable reference profile for comparison with the SSW profile for buoyancy determinations. In later phases, the TS-SW and TS-C profiles become more and more disturbed by the nearby and strengthening intrusions, which do not reach the northeast sidewall. The inflow produces a superadiabatic surface potential temperature profile along the upwind inner sidewall (SSW HOBO line in Fig. 6a). W18 hypothesized that this along-slope potential temperature structure is caused by vertical mixing within the flowing 
layer that produces a progressive increase of surface potential temperatures with downslope distance. The adiabatic lifting of upstream air over the crater rim, the stably stratified flow and katabatic jetlike wind profiles above the rim, the lower potential temperatures on the upwind inner sidewall than on the downwind inner sidewall, and the superadiabatic along-slope potential temperature structure on the upwind sidewall continue during the entire night (Fig. 6).

During the CAI phase, the cold-air inflow (Fig. 5f) turns down the sidewall under the influence of gravity and accelerates from RIM to SSW4. The downslope wind during this phase is too close to the underlying sidewall to be seen in the dual-Doppler wind retrievals (Fig. 6a), but its upper portion is visible in FLR lidar RHI scans (Fig. 8a). Negative vertical velocities at the RIM tower top begin at $2000 \mathrm{MST}$, about $30 \mathrm{~min}$ after the CAI phase begins and when the SBL reaches that level (Fig. 5e). These negative velocities continue through most of the night. The depth to which the CAI will penetrate into the basin depends on the ambient vertical potential temperature structure inside the basin, because the CAI will descend until reaching its level of buoyancy equilibrium (W18). During this phase, a 40-m-deep cold-air pool is present on the basin floor with a potential temperature deficit of $9 \mathrm{~K}$ surmounted by an isothermal layer extending to the rim (Fig. 6a). The isothermal layer is produced through CAI processes documented by Haiden et al. (2011). The CAI can more easily penetrate the nearisothermal layer than the stronger-stability cold pool below. During and following the CAI phase, enhanced cooling within the basin relative to the residual layer aloft produces a potential temperature jump near rim level that strengthens during the night (Figs. 6a-h). During the CAI phase, the close correspondence between potential temperature profiles at TS-SW, TS-C, and NE indicates that isentropes within the bulk of the basin away from the intrusions on the southwest sidewall remain quasi horizontal (Fig. 6a). During the CAI phase, SSW2 is often submerged below the top of the cold pool where winds are calm (Fig. 5f). Wind speed spikes at SSW2 at 1945, 2005, 2045, and 2115 MST coincide with potential temperature minima at the RIM location (Figs. 5f,c), suggesting that the CAI can reach SSW2 only when it has sufficient negative buoyancy to penetrate into or push away the top of the cold pool. Because increases in downslope speed at SSW2 are associated with potential temperature decreases, we can reject the hypothesis that the wind speed excursions are caused by seiches that submerse and reimmerse SSW2 in a sloshing cold pool, as downslope and upslope speed increases would then be associated with potential temperature increases and decreases, respectively.

\section{3) BIfURCATION PHASE, 2130-2245 MST}

W18 previously documented a long-lived (2300-0400 MST) bifurcation phase during IOP7 that occurred when a steady-state katabatic flow developed within a quiescent larger-scale environment. In contrast, the IOP4 bifurcation phase is a relatively short, temporary phase in the ultimate progression to a WAI phase associated with a southwesterly mesoscale flow. Because the bifurcation phase has been previously described, we briefly summarize this phase, pointing out key structural features. The RIM tower was unfortunately not high enough to observe the full depth of the SBL after 0000 MST. Since the lifting of the SBL over the rim was an adiabatic process, however, the structure above the rim can be determined by projecting the portion of the BASE temperature profile in Fig. 6 that is above the dividing streamline upward by the vertical distance between the dividing streamline at BASE and the RIM tower.

The bifurcation phase, initiated by the steady growth of the SBL on the plain (Fig. 4a), begins between 2105 and 2130 MST. By 2210 MST (Fig. 6b), the SBL at RIM is $30 \mathrm{~m}$ deep with a potential temperature deficit of $7.5 \mathrm{~K}$. During the bifurcation phase, the overflowing stably stratified cold air from upstream deepens to the point that it is composed of both a negatively buoyant lower current that runs down the inner sidewall and a nonnegatively buoyant upper current that is advected quasi horizontally over the basin and has a tendency to form unsteady waves in the lee of the rim. The negative vertical velocities at RIM suggest that the two currents pull apart just upwind of the rim. A low-wind speed cavity or "stagnant isolating layer" (Winters and Armi 2014) develops between the two currents. The cavity, with the same isentrope at its base and top, has neutral stability. Cavity potential temperatures, as measured at TS-SW, are warmer than on the undisturbed northeast sidewall, and tethersonde ascents find turbulent air within the cavity. Because the cold current descends into the basin upwind of TS-SW, the capping stable layer above TS-SW and TS-C is missing the cold lower portion that was present at RIM. The bifurcation point is the height above the rim of the potential temperature measured in the cavity (at 2210 MST this is $\sim 27 \mathrm{~m}$ ) rather than, as in the previous phase, the height above the rim of the $\mathrm{NE}^{\prime}$ potential temperature.

During the bifurcation phase, the elevation of the katabatic speed maximum on the plain rises above the rim elevation at 2150 MST (Fig. 4b), with a resulting increase in wind speed from $\sim 2 \mathrm{~m} \mathrm{~s}^{-1}$ at all levels on the RIM tower to $3.8 \mathrm{~m} \mathrm{~s}^{-1}$ at the $3-\mathrm{m} \mathrm{level} \mathrm{and} 5 \mathrm{~m} \mathrm{~s}^{-1}$ at the tower top by the end of the bifurcation phase. Negative vertical velocities at 

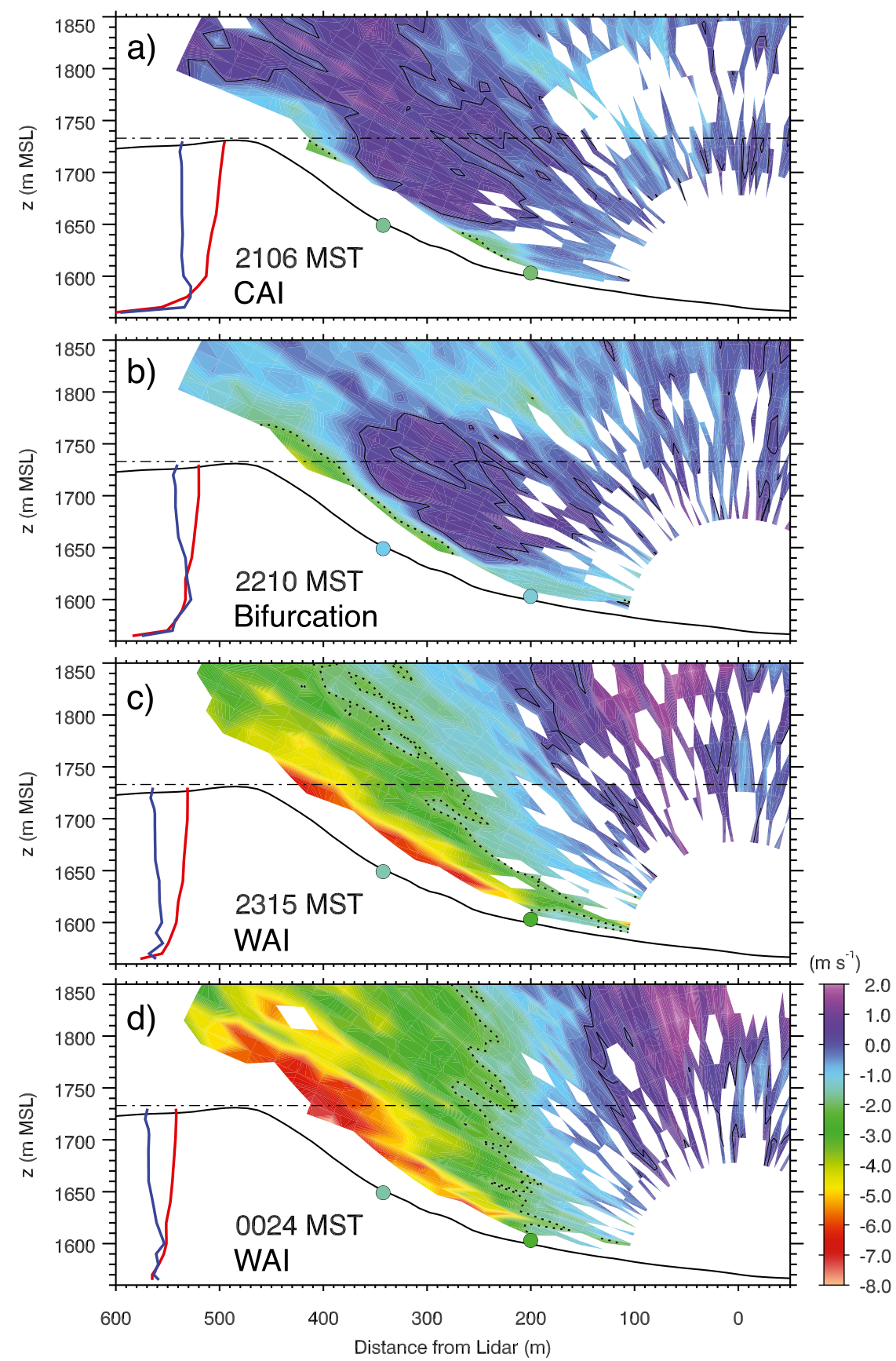

FIG. 8. Individual FLR lidar RHI radial velocity scans at (a) 2106, (b) 2210, (c) 2315, and (d) 0024 MST. Scans are over the upwind inner sidewall in the vertical plane indicated in Fig. 2. The solid black line is the terrain, and the dash-dotted horizontal line at $1733 \mathrm{~m}$ MSL is the RIM tower elevation. Blue and red vertical potential temperature profiles are from the SSW and NE HOBO lines, respectively. The two colored dots on the terrain cross section indicate equivalent radial velocities at $2 \mathrm{~m} \mathrm{AGL}$ at SSW4 and SSW2. Dotted lines highlight the $2 \mathrm{~m} \mathrm{~s}^{-1}$ radial velocity contour.

the top of the tower related to the wave motion in the upper branch of the flow increase from 0.2 to $0.5 \mathrm{~m} \mathrm{~s}^{-1}$ (Fig. 5e). Winds in the stably stratified atmosphere within the capping stable layer are carried across the crater (Fig. 6b), and
RHI scans from the FLR lidar detect the upper part of the shallow CAI (Fig. 8b). The CAI descends the sidewall until reaching and sometimes overshooting its neutral-buoyancy elevation where it initially separates 

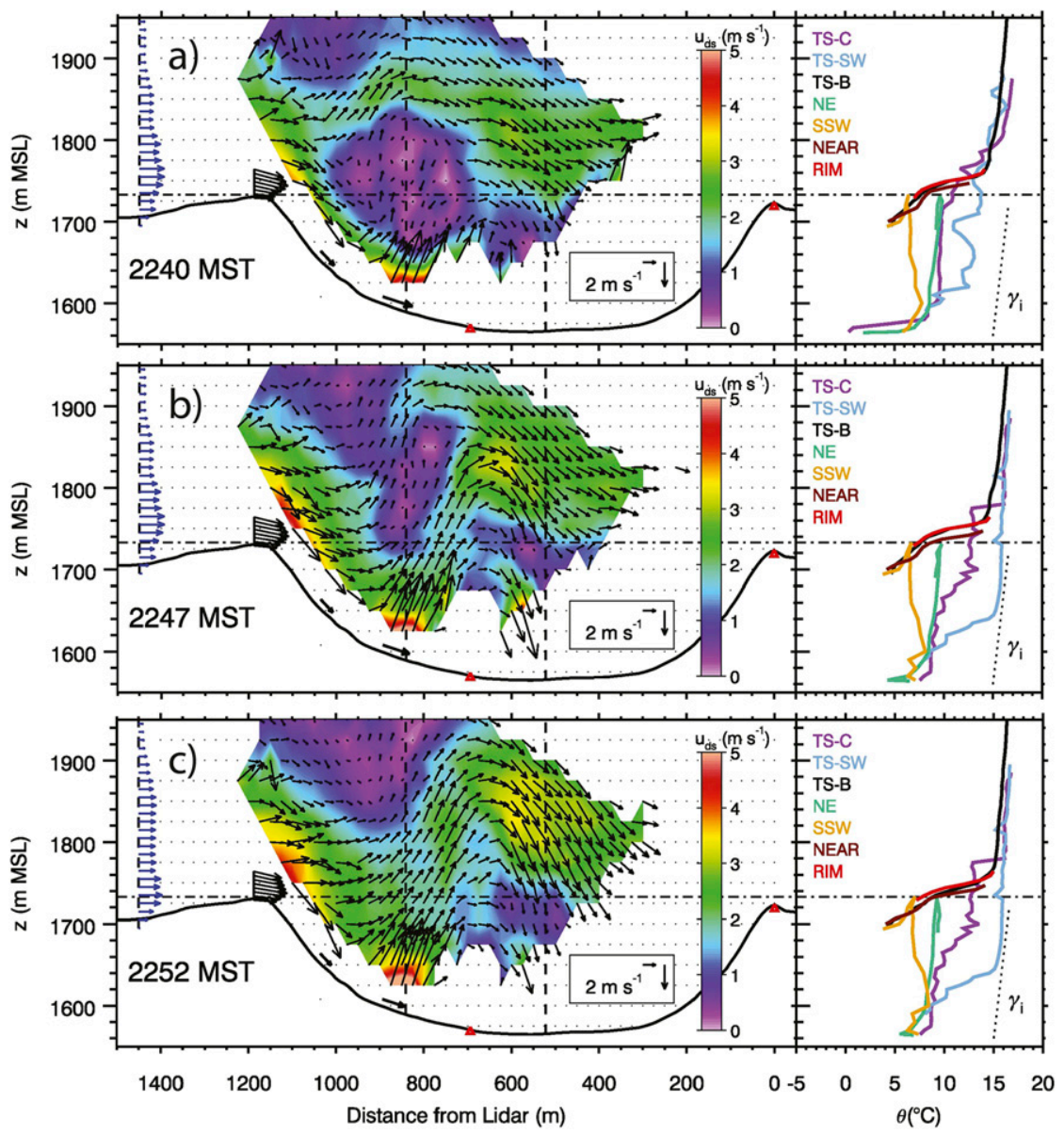

FIG. 9. Illustration of the abrupt change in flow structure between the bifurcation and WAI phases from 2.5-min-mean dual-Doppler wind retrievals at (a) 2240, (b) 2247, and (c) 2252 MST. Potential temperature profiles are identical in (b) and (c). The rest of the figure is as in Fig. 6.

from the slope and runs out into the crater atmosphere (W18). Later in the bifurcation phase as the CAI flow strengthens, a hydraulic jump forms on the lower sidewall as visualized by a zone of rising air above the sidewall (Fig. 9a). These rising motions were not present earlier in the bifurcation phase at 2210 MST (Fig. 6b). Weak speed oscillations occur on the upper and, especially, lower sidewall during the bifurcation phase (Fig. 5f), as they did during the CAI phase.

\section{4) WARM-AIR-INTRUSION PHASE, 2245-0255 MST}

The warm-air-intrusion phase begins around 2245 MST when, in response to increasing downslope winds in the residual layer above the plain SBL (Figs. 4b,c), a lee wave in the upper current of the bifurcation amplifies to bring warm RL air directly down into the crater basin (cf. Figs. 6b and 6c). Dual-Doppler wind field retrievals (Fig. 9) provide a close look at the abruptly changing wind field during this transition. At 2240 MST (Fig. 9a) the bifurcation is still present, with the cavity separating the upper and lower currents and with a hydraulic jump on the lower slope. An unsteady lee wave, however, is present in the statically stable upper current, where wind speeds over the rim have accelerated to $5 \mathrm{~m} \mathrm{~s}^{-1}$ (Fig. 4c). The wave amplifies and descends farther into the basin (Fig. 9b). By 2252 MST (Fig. 9c) the CAI and WAI currents merge, removing the cavity between the two currents and bringing warm RL air down into the basin. The merging of the two currents and the stable layers in which they are embedded increase the stable-layer depth and strength on the sidewall (cf. TS-SW potential temperature profiles in Figs. $6 \mathrm{~b}$ and $6 \mathrm{c}$ ) and increase the downslope wind speeds as well as the layer depth (Figs. $5 \mathrm{f}$ and $8 \mathrm{~b}-\mathrm{d}$ ). The hydraulic jump strengthens (Figs. $6 c, d$ and $9 b, c$ ) as the flow becomes more negatively buoyant relative to the adjacent WAI air and as momentum is transported downward into the stable layer from the WAI. In the bigger picture, the warm descending air over the upwind sidewall is the descending branch of the first wave of a twowave train that extends across the basin with a wavelength 
that is approximately equal to the basin radius and an amplitude that is approximately 2 times the basin depth.

Following the abrupt transition, the WAI continues until 0255 MST during a period in which the maximum downslope winds at BASE and the mean downslope winds on the RIM and NEAR towers remain above $5 \mathrm{~m} \mathrm{~s}^{-1}$ and the downslope wind component in the 80-120 $\mathrm{m}$ AGL layer at BASE is higher than $3 \mathrm{~ms}^{-1}$ (Fig. 4c), along with the downward vertical velocity at the top of the RIM tower generally exceeding $0.6 \mathrm{~m} \mathrm{~s}^{-1}$ (Fig. 5e). During most of the WAI phase, the SSW4 wind speeds are generally about $2.5 \mathrm{~m} \mathrm{~s}^{-1}$ and the winds accelerate down the slope to produce gusty winds of up to $6 \mathrm{~m} \mathrm{~s}^{-1}$ at SSW2 (Fig. 5f). Of interest is that wind speeds decrease at SSW4 when the flow over the rim exceeds $4.5 \mathrm{~m} \mathrm{~s}^{-1}$ - possibly because of a bluff-body flow separation in which the cold overflow is carried some distance over the crater before descending to the underlying sidewall and accelerating to SSW2. The strength and position of the hydraulic jump on the sidewall are variable during the WAI phase, but the rising motions above the jump converge with the rising branch of the lee wave (Figs. 6c-e). Wind speeds on the crater floor (3 $\mathrm{m}$ AGL at FLR) are nearly calm before the WAI but increase intermittently during the WAI, disturbing the cold pool on the basin floor (Fig. 5f).

Following an approach developed by Vogt (2008), a time-lapse sequence of georeferenced thermal infrared temperature [see the animation files in the folder labeled Fig_SI-5 in the online supplemental material (https://doi.org/10.1175/JAMC-D-17-0156.s2) and the accompanying caption (https://doi.org/10.1175/JAMCD-17-0156.s1)] and temperature fluctuation [see the animation files in the folder labeled Fig_SI-6 in the online supplemental material (https://doi.org/10.1175/JAMC-D17-0156.s3) and the accompanying caption (https://doi.org/ 10.1175/JAMC-D-17-0156.s1)] images was used to visualize changes in the effective surface radiating temperature field inside the crater basin as the atmospheric structure progressed through the different phases (Feigenwinter et al. 2016; Grudzielanek et al. 2016). Two frames from the time-lapse thermal infrared temperature sequence illustrate the differences between the CAI and WAI phases (Fig. 10). Both images include the shallow cold pool on the crater floor, the nearly isothermal temperature structure on the sidewalls above the cold pool, and the lower temperatures on the upwind inner sidewall relative to the downwind inner sidewall. The cold pool is roughly circular during the CAI phase (Fig. 10a) but is progressively pushed to the northnortheastern side of the basin as winds strengthen in the WAI phase (Fig. 10b). The unsteady motions in the cold pool during the WAI phase split the cold pool apart and move it around on the crater floor. Turbulent mixing and sinking motions at the top of the cold pool produce warm temperatures at the floor (cf. Fig. $6 \mathrm{~b}$ with Figs. 6c-e), intermittent north-northeast-south-southwestoriented warm streaks on the southwest sidewall and basin floor, and warm and cold patches on the basin floor (Fig. 10b). The flow strength during the WAI phase is, however, insufficient to sweep the cold air from the basin.

The warm-air intrusion is confined over the upwind inner sidewall, as indicated by the simultaneous presence of a capping stable layer at rim level above TS-C and absence above TS-SW (Figs. 6c-e). The depth of penetration of warm RL air into the basin can be estimated from the TS-SW potential temperature sounding, although TS-SW is often somewhat downwind of the wave trough. Ragged below-rim potential temperature profiles at TS-SW in Fig. 6e occur when the tethered balloon ascent path is on the turbulent border between the rising warm RL air and the colder air over the crater center.

The dual-Doppler wind field provides an estimate of the cross-basin spatial variation of the wave boundary between the warm flowing RL air and the colder quiescent air within the basin (Fig. 6). Warm air in the wave trough displaces cold air in the basin. In the following wave crest, cold air is lifted well above the crater rim (Figs. 6c-e) into the warmer environment. Graphics of the wind retrievals over 150-s intervals (Fig_SI-1; https://doi.org/10.1175/ JAMC-D-17-0156.s1) show that the lee wave, while continually present during the WAI phase, is unsteady, with short-term changes in amplitude and position and with intermittent flow separations occurring at different elevations in the descending branch of the lee wave. Other animations (not shown) show vorticity maxima that travel up the cold-air interface over the valley center in the rising branch of the wave, indicating the presence of rotors or Kelvin-Helmholtz instabilities on the interface.

\section{5) Second BIfURCATiOn PHASE, 0255-0410 MST}

Downslope wind speeds in the RL upwind of the crater (e.g., 80-120 m AGL above BASE) and on the NEAR and RIM towers (Fig. 4c) begin a slow decrease midway through the WAI phase. The elevation of the downslope wind speed maximum (Fig. 4b) begins a rapid decrease at 0145 MST, falling from $1860 \mathrm{~m}$ MSL to the crater rim elevation in $1 \mathrm{~h}$. By $0255 \mathrm{MST}$, when the downslope wind speed component at the 40-m level on the RIM tower (Fig. 5d) drops below $6 \mathrm{~m} \mathrm{~s}^{-1}$ a second bifurcation phase is initiated that exhibits a neutral cavity, upper and lower currents, a capping stable layer, and a hydraulic jump (Figs. 6f,g), similar to the evening bifurcation (e.g., Figs. 6b and 9a). Cavity potential temperatures tend to be considerably higher than those on the adjacent slope in the evening bifurcation phase because of the lingering warm air from the preceding WAI phase. 

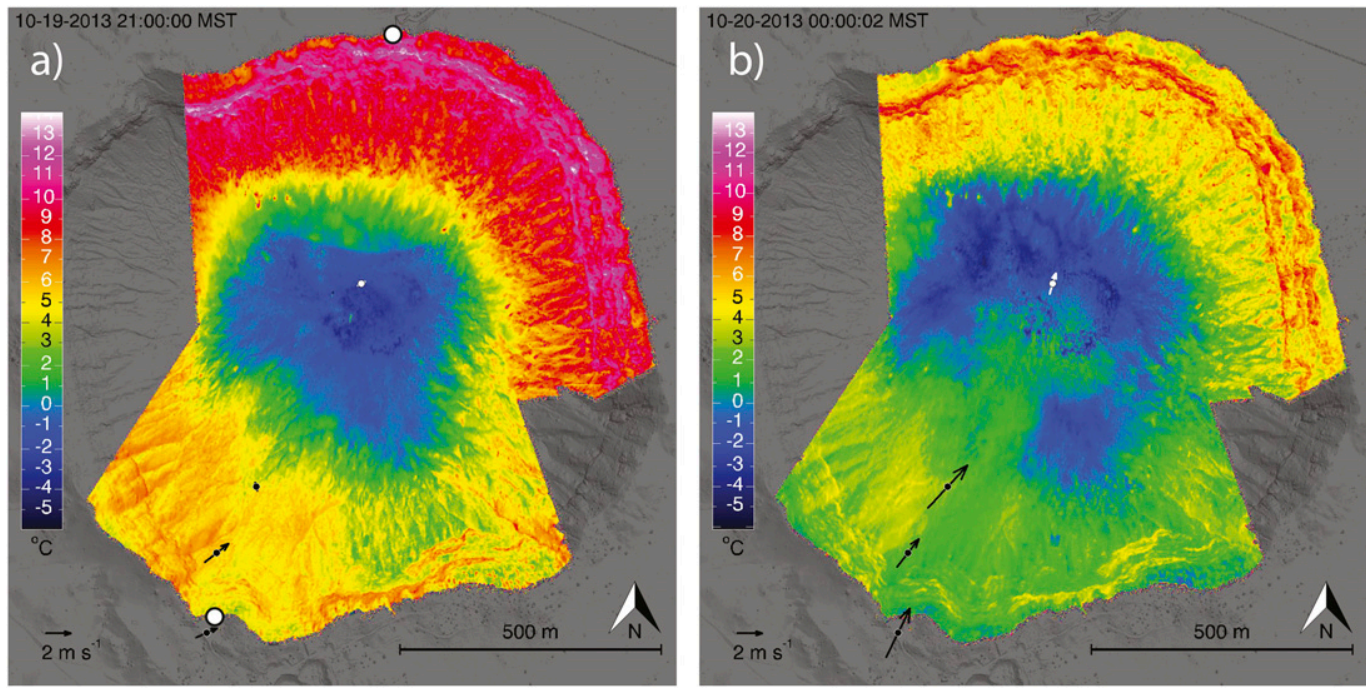

FIG. 10. Georeferenced brightness temperature overlay on the Meteor Crater topography at (a) 2100 and (b) 0000 MST. Adjusted brightness temperature data come from three thermal infrared cameras, two operated side by side on the north rim looking south-southwest and one on the south rim looking north-northeast. The camera locations are shown as white dots in (a). Horizontal wind vectors are shown in black at RIM, SSW4, and SSW2 and in white at FLR.

\section{6) SECOND COLD-AIR-INTRUSION PHASE, 0410-0600 MST}

During most of the night, mesoscale winds in the RL have a downslope component that is in the same direction as the underlying katabatic flow on the plain below. Around 0410 MST, however, the mesoscale flow above the crater becomes northwesterly (Fig. 4b), counter to the underlying katabatic flow, reducing the depth and strength of the katabatic flow coming over the rim and causing the flow to make a transition into a second CAI phase. By 0510 MST (Fig. 6h), the wind component in the vertical plane above the crater is upslope at elevations above $1780 \mathrm{~m}$ MSL. The upper and lower currents, the cavity, and the hydraulic jump disappear and only a weak, shallow CAI comes over the southwest rim. The cold-air overflow in this phase has a potential temperature deficit relative to the downwind rim of about $3 \mathrm{~K}$ (Fig. 7), similar to that in the evening CAI phase and throughout the entire night. Wind speeds decrease on the lower sidewall and become calm on the crater floor (Fig. 5f). The cold pool restrengthens (Fig. 6h) and potential temperature profiles become similar to those in the first CAI phase $8 \mathrm{~h}$ earlier (Fig. 6a).

\section{Discussion}

\section{a. Conceptual model}

The sequential development of phases, including the penultimate WAI phase that produced the strongest turbulent winds on the lower sidewall, is an interesting aspect of IOP4 that extends the previous study of a 5-h-long steady-state bifurcation period during IOP7 (W18). The cyclical development of the phases in IOP4 is produced by temporal changes in the characteristics of the approaching flow.

The depth of the stable layer on the plain (Fig. 4a) increases monotonically through the night, and the negative buoyancy of the cold-air overflow at the rim relative to the downwind rim changes little during the night (Fig. 7). These monotonically increasing and/or steady approach-flow characteristics cannot, in themselves, be responsible for the full cycle of phases experienced inside the basin. The growth of the SBL on the plain and the advection of cold air from this SBL over the rim by the locally driven katabatic flow play major roles in the CAI and bifurcation phases, but the cyclical nature of the downslope component of the winds in the $\mathrm{RL}$ above the plain SBL plays the major role in bringing the basin atmosphere through the WAI phase.

A two-dimensional conceptual model of the mean structure of the overflow-initiation, cold-air-intrusion, bifurcation, and warm-air-intrusion phases on a vertical cross section through the crater basin is presented in Fig. 11 by combining analyses from section 4 . Nonstationary and three-dimensional aspects of the flow are not addressed in this figure, although they are clearly present in the observations.

\section{b. Interesting aspects of the phases}

The lifting of a cold stably stratified layer over the rim by a katabatic flow that develops in the SBL on the 

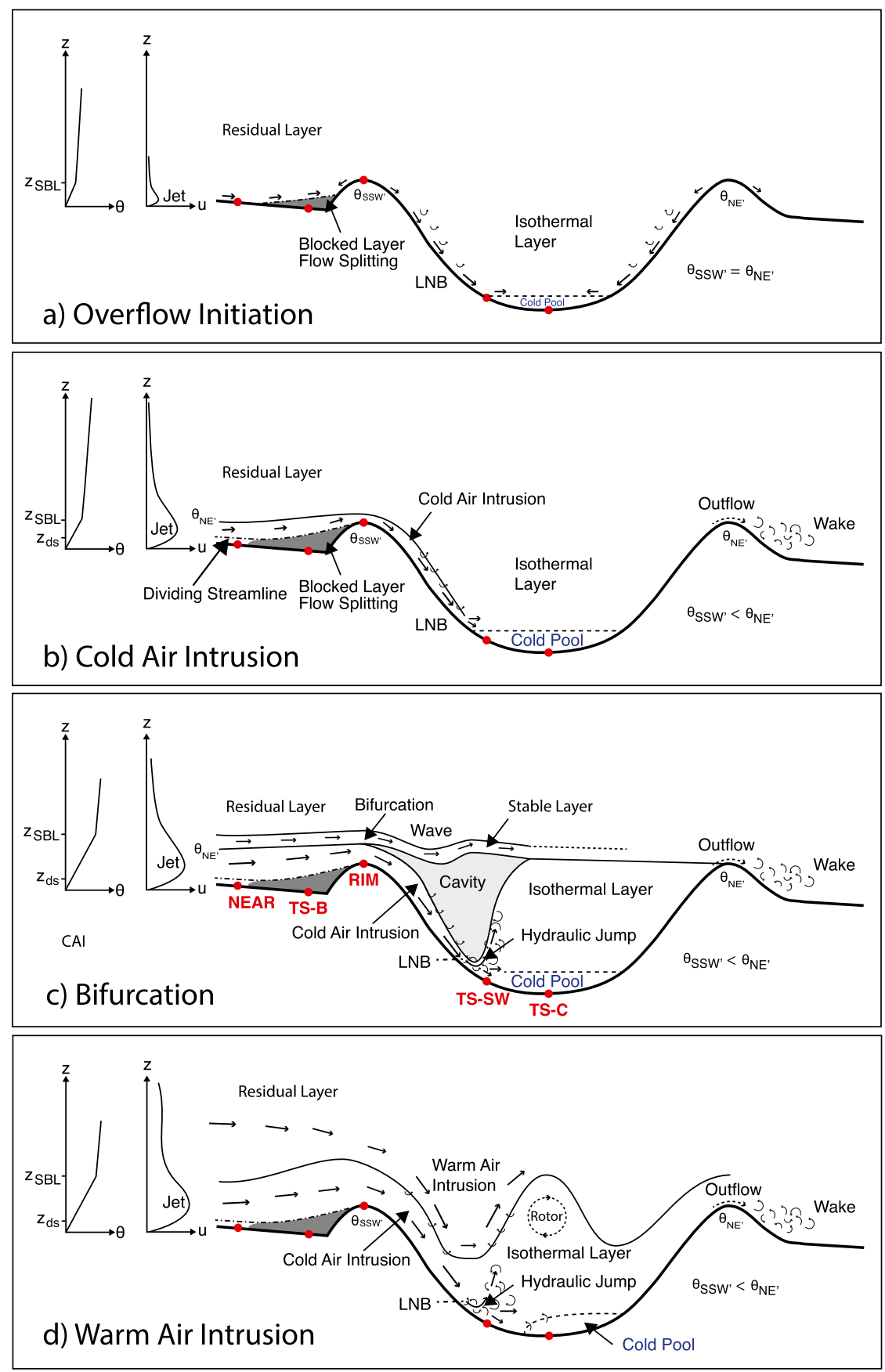

FIG. 11. A two-dimensional conceptual diagram (not to scale) of the (a) overflow-initiation, (b) CAI, (c) bifurcation, and (d) WAI phases. Profiling sites are at the labeled red dots in (c). Vectors are 2D winds; solid lines above the terrain are selected isentropes. Dashed lines indicate the isentrope at the top of the cold pool. The dot-dashed line represents the top of the blocked stable layer in (a) and the dividing streamline in (b)-(d). The $z_{\mathrm{SBL}}$ and $z_{\mathrm{ds}}$ are the SBL and dividing streamline heights on the plain far upwind of the crater. The $\theta_{\mathrm{NE}^{\prime}}$ and $\theta_{\mathrm{SSW}^{\prime}}$ are $\mathrm{NE}$ and SSW rim temperatures. Panel (b) is modified from a figure in W18. LNB is the level of neutral buoyancy.

upwind plain initiates the cold-air-intrusion phase. The continuous negatively buoyant airflow coming over the rim appears to be an atmospheric analog to hydraulic flows occurring in flumes and weirs (e.g., Massey and Ward-Smith 2006) or over underlying topography in oceans or lakes (Armi and Farmer 2002). 
They bear similarities to other atmospheric "hydraulic" flows over mountains in which bifurcations, cavities, and strong surface winds and hydraulic jumps have been noted (Winters and Armi 2014). The strength of the descending CAI current in the CAI and bifurcation phases appears to depend on the along-slope integrated negative buoyancy on the south-southwest slope relative to the undisturbed northeast slope (W18). The important role of negative buoyancy in the acceleration of descending flows in the lee of topography is supported by the work of Armi and Mayr (2011). CAI speeds in the WAI phase are enhanced by downward momentum transport from the intruding lee wave.

The deepening of the overflowing stable layer results in a bifurcation of the flow into a negatively buoyant layer that runs down the inner sidewall while the upper, stably stratified layer is carried over the crater. A hydraulic jump occurs in the cold airstream on the lower sidewall near the end of this phase. The transition into the WAI phase is produced by an enhancement of katabatic flow strength by a mesoscale flow that develops in the RL; this mesoscale flow enhancement was not present in IOP7 when no WAI was produced (W18). Warm RL air is brought down into the basin behind the upwind rim by a lee wave whose wavelength is approximately one-half of the crater diameter (i.e., $600 \mathrm{~m}$ ). Numerical simulations by Lehner et al. (2016b) and Rotunno and Lehner (2016) found similar two-wave regimes in an idealized Meteor Crater. Descending motions on the RIM tower place the initial wave crest upwind of the rim, suggesting that the approaching flow may be responding to the crater's "effective topography" (Armi and Mayr 2015), in which a cold-air "obstacle" builds up on the windward side of the crater, or that the phase line of the wave is tilting upstream (Fritts et al. 2010).

The prominent two-wave pattern inside the crater appears to be a dynamic accommodation of the atmospheric flows to the wavelength of the underlying terrain, a feature of previous numerical modeling studies of flows into basins (Soontiens et al. 2013; Lehner et al. 2016b; Rotunno and Lehner 2016) or across a valley confined between mountain ranges (Lee et al. 1987; Vosper 1996; Grubišić and Stiperski 2009; Stiperski and Grubišić 2011).

\section{c. Instability leading to the WAI phase}

We hypothesize that the lee wave forms and deepens through a shear instability mechanism as the increasing $\mathrm{RL}$ downslope wind component increases the positive vertical wind shear across the capping stable layer. This instability brings the capping stable-layer interface downward into the upper-crater atmosphere, allowing the RL winds to descend into the crater. A necessary condition for the development of this wave is that the Richardson number ( $\mathrm{Ri}$ ) must fall below a critical value in the density interface zone somewhat upwind of the crater rim where the instability forms. The critical Richardson number is usually taken as 0.25 (Nappo 2012), from linear stability analysis. Other formulations and empirical studies have suggested slightly different critical values. Richardson-number computations are complicated by the noncontinuous nature of the tethersonde soundings, their nonideal locations (TS-B and TS-SW are upwind and downwind of the wave-initiation zone), the turbulent motions that buffet the wind sensors on the tether line below the TS-SW balloon, and the fact that some TS-SW soundings ascended through the boundary between the warm air and the colder air in the crater center. Nonetheless, observational evidence during the bifurcation-to-WAI transition provides support for this mechanism (Fig. 12). On the plain at TS-B (Fig. 12a), Ri reaches the critical 0.25 threshold in the surface layer during the OI phase, continuing all night. A zone of low $\mathrm{Ri}$ is also generated just above the top of the growing SBL by the wind shear and low stability there. This low-Ri layer reaches the rim level at the beginning of the CAI phase; Ri then drops below 0.25 near the middle of the bifurcation phase. The low-Ri zone above the SBL continues its rise above the rim during the rest of the night, but low values return to the rim level at the end of the second bifurcation phase. Within the basin at TS-SW (Fig. 12b), Ri near the surface varies with time as the site is alternately exposed to and protected from the CAI; Ri drops below 0.25 at the rim elevation at the beginning of the CAI phase and continues through most of the night until the beginning of the second bifurcation phase. The full depth of the basin and the atmosphere above maintains $\mathrm{Ri}<0.25$ during the WAI phase (except for short-term excursions caused by the factors mentioned above). Higher values of $\mathrm{Ri}$ are generally found above TS-SW in the upper elevations of the basin during the CAI phases when weak winds and low stability are present and intermittently in the bifurcation phases when the cavity is near neutral with low wind speeds. Sachsperger et al. (2015) investigated this shear-instability mechanism in the lee of a ridge using numerical simulations for a situation similar to that for the bifurcation phase (vertical wind shear across a density interface zone with a neutral layer below and a stable layer above).

\section{d. Need for further research}

Data weaknesses limit confidence in some aspects of the analyses. Field data cannot determine if detrainment is occurring at the top of the cold-air intrusion. Numerical and laboratory simulations by Baines (2005) suggest that both entrainment and detrainment are possible depending on slope angle. The turbulentmixing mechanism that we posited as leading to the 


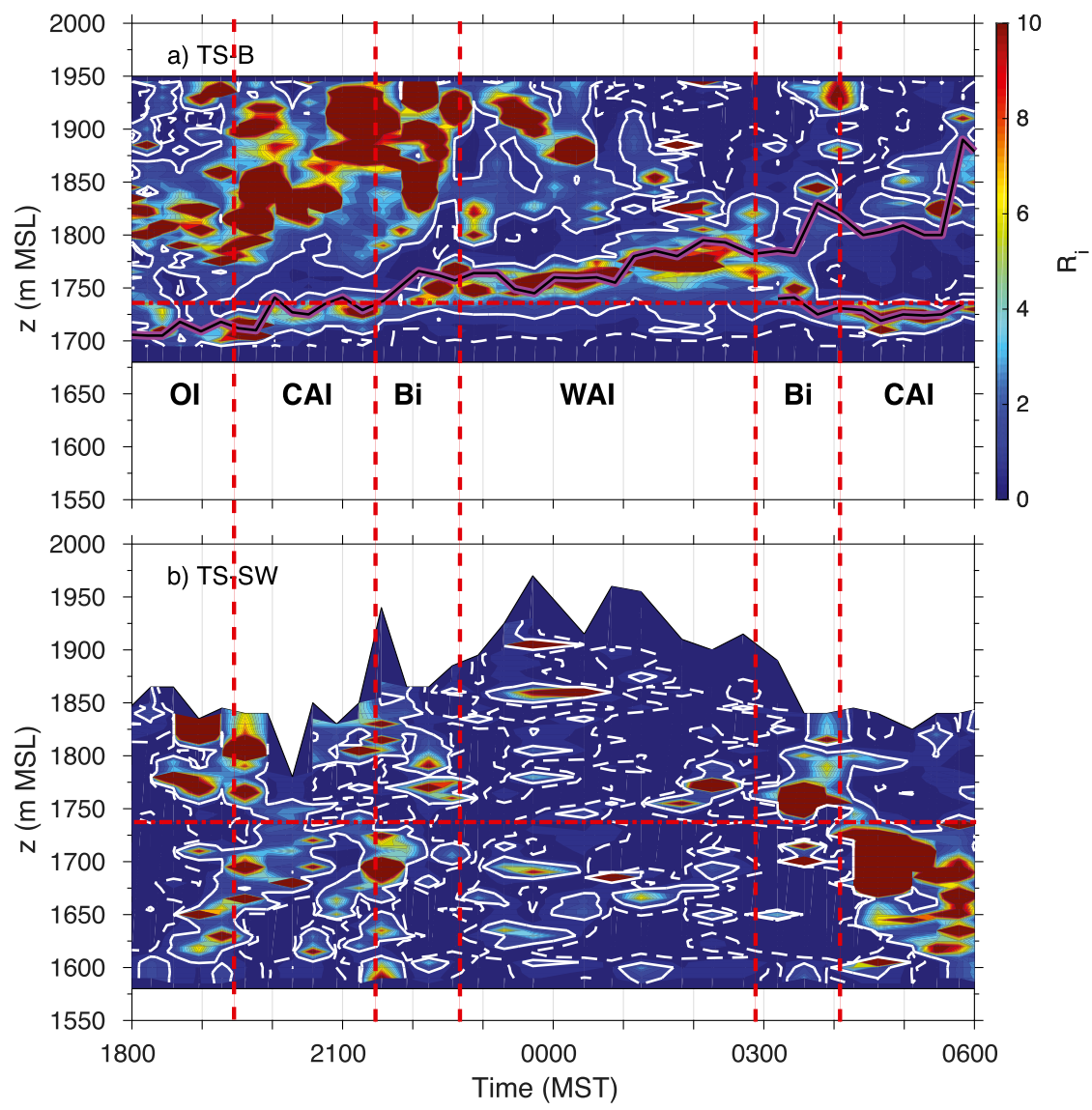

FIG. 12. Time-height cross section of Richardson number at (a) TS-B and (b) TS-SW. Solid and dashed white contour lines are for $\mathrm{Ri}=1$ and $\mathrm{Ri}=0.25$, respectively. Time boundaries between the different phases are indicated by the red vertical dashed lines. The rim elevation is indicated by the red horizontal dash-dotted line on both (a) and (b). The black lines with purple backgrounds in (a) are stable layer tops repeated from Fig. 4a.

superadiabatic, along-slope potential temperature profile within the flowing CAI also cannot be verified with current observations. The relative roles of the negative buoyancy increase and downward momentum transport from the overlying WAI in accelerating the CAI and strengthening the hydraulic jump cannot be determined from the observations. The lack of a uniform stable environment inside the crater for determining the negative buoyancy of intruding air parcels is an issue that needs further research. Our choice of time-varying, relatively undisturbed northeast-sidewall potential temperature profiles for environmental soundings is a useful first approach. Additional numerical simulations and field studies may answer some of these questions.

\section{Summary}

A case study has focused on the interactions between an approaching southwesterly katabatic flow that formed on a $1^{\circ}$-tilted mesoscale plain and a basin with a surrounding 30-50-m-high rim that was formed on the plain by a meteorite impact. The interaction between the nighttime katabatic flow and the crater basin on the night of 19-20 October (IOP4) is the atmospheric equivalent of a "hydraulic flow" that evolves through six well-defined phases, four of which are illustrated in the conceptual model of Fig. 11. The overflow-initiation phase includes the initiation and growth of separate stable boundary layers and katabatic flows over the plain and inside the basin. Above a dividing streamline, the katabatic flow lifts the cold air in the plain SBL up the outer sidewall of the crater. In the cold-air-intrusion phase, cold air from the plain SBL overflows the rim and, because it is negatively buoyant relative to air within the crater, descends the upwind inner sidewall and flows down the sidewall until it reaches its level of neutral buoyancy and flows out into the main-crater atmosphere. As the plain SBL deepens and the katabatic flow 
increases in strength, the flow bifurcation phase begins in which the lower negatively buoyant portion of the stable layer continues to flow down the inner sidewall while an upper nonnegatively buoyant portion is carried over the crater in a quasi-horizontal overflow. A cavity forms between the two branches of the bifurcation that contains near-neutral stability and low wind speeds. A shallow unsteady wave forms in the lee of the rim in the upper layer, and a hydraulic jump forms above the lower sidewall in the lower descending layer. As the SBL on the plain deepens, a mesoscale downslope flow in the residual layer becomes superimposed on the katabatic flow, initiating a warm-airintrusion phase. The unsteady wave in the lee of the rim amplifies and brings the upper nonnegatively buoyant stable layer down into the crater above the cold-air intrusion, carrying warm air directly into the upper elevations of the basin from the residual layer above the plain. Rising air in the hydraulic jump over the lower sidewall merges with the rising branch of the lee wave. The disturbances produced by these phases are largely confined above the upwind inner sidewall, but the strong and turbulent flow near the base of the southwest sidewall during the flow-bifurcation and warm-air-intrusion phases disturbs the preexisting shallow cold pool on the crater floor. Decreases in wind speeds in the residual layer above the crater later in the night cause the warm-air-intrusion phase to make a transition back to the flow-bifurcation and then cold-air-intrusion phases before sunrise.

Potential temperature and wind profile observations inside and outside the crater basin and, especially, dualDoppler wind retrievals inside the basin were critical to the above analyses, adding new information on the katabatic flow that produces a continuous cold-air intrusion into the closed basin, the role of SBL growth on the plain in producing a flow bifurcation above the basin, and the effect of preexisting and evolving basin potential temperature profiles on the buoyancy of air descending into the basin. The negative buoyancy of the cold-air inflow can lead to relatively strong winds and the formation of a hydraulic jump on the lower sidewall of even a small basin. Weak-tomoderate winds aloft can modulate the katabatic overflow to produce lee waves and warm-air intrusions. It is hoped that these analyses will stimulate future numerical modeling of katabatically driven flows into basins.

Acknowledgments. This paper is dedicated to the memory of Dr. Thomas W. Horst, a cherished colleague who led the NCAR Earth Observing Laboratory's field and data-processing support for this project, including the construction and instrumentation of the two tall towers. We greatly appreciate the assistance of the many METCRAX II participants, property owners, and lenders of field equipment who were acknowledged or served as coauthors in the Lehner et al. (2016b) article. We thank Drs. Rich Rotunno, Georg Mayr, and Iva Stiperski for useful discussions and two anonymous reviewers for their comments. This research was supported by NSF's Physical and Dynamic Meteorology Division (B. Smull and E. Bensman) through Grant AGS-1160730. The contribution of the Karlsruhe Institute of Technology was funded by the International Bureau of the German Bundesministerium für Bildung und Forschung under Grant 01 DM 13002.

\section{APPENDIX}

\section{Alternative Potential Temperature}

Potential temperature is defined as

$$
\theta=T\left(p_{0} / p\right)^{R / c_{p}},
$$

where $p$ and $T$ are the measured pressure (hPa) and temperature $(\mathrm{K})$, respectively, $R$ is the gas constant, $c_{p}$ is the specific heat of air at constant pressure, and $p_{0}(\mathrm{hPa})$ is an arbitrary reference pressure usually taken as $1000 \mathrm{hPa}$. Parcel stability considerations do not depend on the specific value of $p_{0}$. Using the pressure at the crater floor $p_{f}$ as the reference pressure, the crater-floor potential temperature becomes

$$
\theta_{f}=T\left(p_{f} / p\right)^{R / c_{p}} .
$$

A simplified way of reducing temperature to the level of the crater floor is given by

$$
\theta_{f}=T+\Gamma\left(z-z_{f}\right)
$$

where $\Gamma=g / c_{p}$ is the dry-adiabatic lapse rate $\left(0.0098 \mathrm{~K} \mathrm{~m}^{-1}\right)$, and $g$ is the gravitational acceleration. This method is useful for checking static stability in cases in which temperature data are available at sites without pressure data. The following analysis shows the relationship between Eqs. (A3) and (A2).

The decrease of pressure with elevation in a hydrostatic atmosphere with temperature lapse rate $\gamma=-d T / d z$ is given by

$$
p(z)=p_{f}\left[1-\frac{\gamma\left(z-z_{f}\right)}{T_{f}}\right]^{g /(R \gamma)},
$$

where $T_{f}$ denotes temperature at the crater floor. A more complicated temperature profile can be considered by treating it as piecewise linear. The hydrostatic assumption is justified by the limited flow speeds 
(generally below $10 \mathrm{~m} \mathrm{~s}^{-1}$ ) in the crater. Inserting Eq. (A4) into Eq. (A2) gives

$$
\theta=T\left[1-\frac{\gamma\left(z-z_{f}\right)}{T_{f}}\right]^{-\Gamma / \gamma} .
$$

If the temperature difference across the layer of interest $\gamma\left(z-z_{f}\right)$ is much smaller than $T_{f}$ we can linearize Eq. (A5), retaining only the first two terms of the binomial expression in the form

$$
(1-x)^{n} \approx 1-x n
$$

to obtain

$$
\theta=T+\frac{T}{T_{f}} \Gamma\left(z-z_{f}\right) .
$$

Equation (A7) is similar to Eq. (A3), except for the multiplicative factor $T / T_{f}$. The smaller the temperature range across the layer of interest is, the closer this factor is to 1. For shallow atmospheric layers, Eq. (A3) is therefore a good approximation to Eq. (A2), and in the isothermal limit Eq. (A3) becomes exact.

How good an approximation is Eq. (A3) in comparison with Eq. (A2) when applied to METCRAX temperature profiles? The largest potential temperature difference between the two methods occurs in the calculation of potential temperature at the top of a deep and strong temperature inversion. For IOP4 this would be a $14^{\circ} \mathrm{C}$ inversion over a depth of $250 \mathrm{~m}$. Constructing a hypothetical hydrostatic linear inversion profile upward from a surface temperature of $0^{\circ} \mathrm{C}(273 \mathrm{~K})$, the potential temperature difference between the two methods for the $14^{\circ} \mathrm{C}$ point at the top of the sounding is $0.07 \mathrm{~K}$-more than two orders of magnitude smaller than the temperature difference across the profile. Therefore, the classification of superadiabatic versus stable layers remains valid. Across strongly stratified layers such as near the crater floor, differences are small as well because of the limited depth of such layers. For a stable layer of $5 \mathrm{~K}$ over $50 \mathrm{~m}, \theta$ from the two methods differs by about $0.01 \mathrm{~K}$.

\section{REFERENCES}

Adler, B., C. D. Whiteman, S. W. Hoch, M. Lehner, and N. Kalthoff, 2012: Warm-air intrusions in Arizona's Meteor Crater. J. Appl. Meteor. Climatol., 51, 1010-1025, https:// doi.org/10.1175/JAMC-D-11-0158.1.

Armi, L., and D. Farmer, 2002: Stratified flow over topography: Bifurcation fronts and transition to the uncontrolled state. Proc. Roy. Soc., 458A, 513-538, https://doi.org/10.1098/ rspa.2001.0887.
_ - and G. J. Mayr, 2011: The descending stratified flow and internal hydraulic jump in the lee of the Sierras. J. Appl. Meteor. Climatol., 50, 1995-2011, https://doi.org/10.1175/ JAMC-D-10-05005.1.

_ and - 2015: Virtual and real topography for flows across mountain ranges. J. Appl. Meteor. Climatol., 54, 723-731, https://doi.org/10.1175/JAMC-D-14-0231.1.

Baines, P. G., 2005: Mixing regimes for the flow of dense fluid down slopes into stratified environments. J. Fluid Mech., 538, 245267, https://doi.org/10.1017/S0022112005005434.

Browning, K. A., and R. Wexler, 1968: The determination of kinematic properties of a wind field using Doppler radar. J. Appl. Meteor., 7, 105-113, https://doi.org/10.1175/1520-0450 (1968)007<0105:TDOKPO >2.0.CO;2.

Byers, H. R., 1959: General Meteorology. 3rd ed. McGraw-Hill, $540 \mathrm{pp}$.

Cherukuru, N. W., R. Calhoun, M. Lehner, S. W. Hoch, and C. D. Whiteman, 2015: Instrument configuration for dual Doppler lidar co-planar scans: METCRAX II. J. Appl. Remote Sens., 9, 096090, https://doi.org/10.1117/1.JRS.9.096090.

De Wekker, S. F. J., and C. D. Whiteman, 2006: On the time scale of nocturnal boundary layer cooling in valleys and basins and over plains. J. Appl. Meteor., 45, 813-820, https://doi.org/ 10.1175/JAM2378.1.

Feigenwinter, I., R. Vogt, M. Müller, E. Parlow, M. Grudzielanek, M. Lehner, S. W. Hoch, and C. D. Whiteman, 2016: Analysis of flow structures in the Barringer Meteor Crater using thermal infrared data collected during the METCRAX II field experiment. 22nd Symp. on Boundary Layers and Turbulence, Salt Lake City, UT, Amer. Meteor. Soc., 9A.2, https://ams.confex.com/ams/ 32AgF22BLT3BG/webprogram/Paper295047.html.

Fritts, D. C., D. Goldstein, and T. Lund, 2010: High-resolution numerical studies of stable boundary layer flows in a closed basin: Evolution of steady and oscillatory flows in an axisymmetric Arizona Meteor Crater. J. Geophys. Res., 115, D18109, https://doi.org/10.1029/2009JD013359.

Glickman, T. S., Ed., 2000: Glossary of Meteorology. 2nd ed. Amer. Meteor. Soc., 855 pp., http://glossary.ametsoc.org/.

Grubišić, V., and I. Stiperski, 2009: Lee-wave resonances over double bell-shaped obstacles. J. Atmos. Sci., 66, 1205-1228, https://doi.org/10.1175/2008JAS2885.1.

Grudzielanek, A. M., M. Maric, R. Vogt, J. Cermak, I. Feigenwinter, C. D. Whiteman, M. Lehner, and S. W. Hoch, 2016: Cold-air pool analysis using thermal imaging from Arizona's Meteor Crater during METCRAX II. 22nd Symp. on Boundary Layers and Turbulence/32nd Conf. on Agricultural and Forest Meteorology, Salt Lake City, UT, Amer. Meteor. Soc., 34, https://ams.confex.com/ams/32AgF22BLT3BG/webprogram/ Paper295263.html.

Haiden, T., C. D. Whiteman, S. W. Hoch, and M. Lehner, 2011: A mass flux model of nocturnal cold-air intrusions into a closed basin. J. Appl. Meteor. Climatol., 50, 933-943, https://doi.org/ 10.1175/2010JAMC2540.1

Hoch, S. W., and C. D. Whiteman, 2010: Topographic effects on the surface radiation balance in and around Arizona's Meteor Crater. J. Appl. Meteor. Climatol., 49, 1114-1128, https://doi.org/10.1175/2010JAMC2353.1.

—_, _ _ and B. Mayer, 2011: A systematic study of longwave radiative heating and cooling within valleys and basins using a three-dimensional radiative transfer model. J. Appl. Meteor. Climatol., 50, 2473-2489, https://doi.org/ 10.1175/JAMC-D-11-083.1. 
Jackson, P. L., G. Mayr, and S. Vosper, 2013: Dynamically-driven winds. Mountain Weather Research and Forecasting, F. K. Chow, S. F. J. DeWekker, and B. Snyder, Eds., Springer, 121-218.

Kiefer, M. T., and S. Zhong, 2011: An idealized modeling study of nocturnal cooling processes inside a small enclosed basin. J. Geophys. Res., 116, D20127, https://doi.org/10.1029/ 2011JD016119.

Kring, D. A., 2007: Guidebook to the Geology of Barringer Meteorite Crater, Arizona (a.k.a. Meteor Crater). Lunar and Planetary Institute, $150 \mathrm{pp}$.

Lee, J. T., R. E. Lawson, and G. L. Marsh, 1987: Flow visualization experiments on stably stratified flow over ridges and valleys. Meteor. Atmos. Phys., 37, 183-194, https://doi.org/10.1007/ BF01042440.

Lehner, M., and Coauthors, 2016a: The METCRAX II field experiment-A study of downslope windstorm-type flows in Arizona's Meteor Crater. Bull. Amer. Meteor. Soc., 97, 217-235, https://doi.org/10.1175/BAMS-D-14-00238.1.

- , R. Rotunno, and C. D. Whiteman, 2016b: Flow regimes over a basin induced by upstream katabatic flows-An idealized modeling study. J. Atmos. Sci., 73, 3821-3842, https:// doi.org/10.1175/JAS-D-16-0114.1.

Leo, L. S., M. Y. Thompson, S. Di Sabatino, and H. J. S. Fernando, 2016: Stratified flow past a hill: Dividing streamline concept revisited. Bound.-Layer Meteor., 159, 611-634, https://doi.org/ 10.1007/s10546-015-0101-1.

Martinez-Villagrassa, D., M. Lehner, C. D. Whiteman, S. W. Hoch, and J. C. Cuxart-Rodamilans, 2013: The upslope-downslope flow transition on a basin sidewall. J. Appl. Meteor. Climatol., 52, 2715-2734, https://doi.org/10.1175/JAMC-D-13-049.1.

Massey, B., and J. Ward-Smith, 2006: Mechanics of Fluids. 8th ed. Taylor and Francis, 696 pp.

Nappo, C. J., 2012: An Introduction to Atmospheric Gravity Waves. 2nd ed. Elsevier, 359 pp.

Rotunno, R., and M. Lehner, 2016: Two-layer stratified flow past a valley. J. Atmos. Sci., 73, 4065-4076, https://doi.org/10.1175/ JAS-D-16-0132.1.

Sachsperger, J., S. Serafin, and V. Grubišić, 2015: Lee waves on the boundary-layer inversion and their dependence on freeatmospheric stability. Front. Earth Sci., 3, 70, https://doi.org/ 10.3389/feart.2015.00070.
Savage, L. C., I. Crosby, S. Zhong, W. Yao, W. J. O. Brown, T. W. Horst, and C. D. Whiteman, 2008: An observational and numerical study of a regional-scale downslope flow in northern Arizona. J. Geophys. Res., 113, D14114, https://doi.org/ 10.1029/2007JD009623.

Smith, R. B., 1989: Hydrostatic airflow over mountains. Advances in Geophysics, Vol. 31, Academic Press, 1-41, https://doi.org/ 10.1016/S0065-2687(08)60052-7.

Soontiens, N., M. Stastna, and M. L. Waite, 2013: Numerical simulations of waves over large crater topography. J. Atmos. Sci., 70, 1216-1232, https://doi.org/10.1175/JAS-D-12-0221.1.

Stiperski, I., and V. Grubišić, 2011: Trapped lee wave interference in the presence of surface friction. J. Atmos. Sci., 68, 918-936, https://doi.org/10.1175/2010JAS3495.1.

Vogt, R., 2008: Visualisation of turbulent exchange using a thermal camera. 18th Symp. on Boundary Layers and Turbulence, Stockholm, Sweden, Amer. Meteor. Soc., 8B.1, https://ams. confex.com/ams/18BLT/techprogram/paper_140094.htm.

Vosper, S., 1996: Gravity-wave drag on two mountains. Quart. J. Roy. Meteor. Soc., 122, 993-999, https://doi.org/10.1002/qj.49712253211.

Whiteman, C. D., and Coauthors, 2008: METCRAX 2006: Meteorological experiments in Arizona's Meteor Crater. Bull. Amer. Meteor. Soc., 89, 1665-1680, https://doi.org/10.1175/ 2008BAMS2574.1.

— S. W. Hoch, M. Lehner, and T. Haiden, 2010: Nocturnal coldair intrusions into a closed basin: Observational evidence and conceptual model. J. Appl. Meteor. Climatol., 49, 1894-1905, https://doi.org/10.1175/2010JAMC2470.1.

— M. Lehner, S. W. Hoch, B. Adler, N. Kalthoff, and T. Haiden, 2018: Katabatically driven cold air intrusions into a basin atmosphere. J. Appl. Meteor. Climatol., 57, 435-455, https:// doi.org/10.1175/JAMC-D-17-0131.1.

Wilczak, J. M., S. P. Oncley, and S. A. Stage, 2001: Sonic anemometer tilt correction algorithms. Bound.-Layer Meteor., 99, 127-150, https://doi.org/10.1023/A:1018966204465.

Winters, K. B., and L. Armi, 2014: Topographic control of stratified fluids: Upstream jets, blocking and isolating layers. J. Fluid Mech., 753, 80-103, https://doi.org/10.1017/jfm.2014.363.

Zardi, D., and C. D. Whiteman, 2013: Diurnal mountain wind systems. Mountain Weather Research and Forecasting, F. K. Chow, S. F. J. DeWekker, and B. Snyder, Eds., Springer, 35-119. 